\title{
Environmental influences on the diel timing of spawning in coral reef fishes
}

\author{
Gorka Sancho $^{1, *}$, Andrew R. Solow ${ }^{2}$, Phillip S. Lobel ${ }^{3}$ \\ ${ }^{1}$ Department of Biology, Woods Hole Oceanographic Institution, Woods Hole, Massachusetts 02543, USA \\ ${ }^{2}$ Andrew R. Solow, Marine Policy Center, Woods Hole Oceanographic Institution, Woods Hole, Massachusetts 02543, USA \\ ${ }^{3}$ Boston University Marine Program, Woods Hole, Massachusetts 02543, USA
}

\begin{abstract}
Multiple hypotheses have been proposed regarding the adaptive nature of different diel reproductive cycles observed in coral reef fishes. This study quantified the spawning patterns of 11 different reef fish species at Johnston Atoll (Central Pacific), while making simultaneous measurements of the environmental factors likely to affect their spawning behaviors. The environmental variables measured (time of day, tides, current velocity, current speed and abundance of piscivores) were correlated with observed spawning outputs through multifactorial analyses. High interspecific variability in spawning patterns was found among the 11 monitored species. The majority of species spawned at a specific time of the day, in agreement with the timing of spawning described at other locations, indicative of a fixed general response by fishes across distribution areas. Spawning of most fishes with daytime spawning peaks was correlated with local changes in current direction and predatory risks, suggesting responses designed to reduce the mortality of propagules and adults. Dusk-spawning species generally did not respond to changes in flow direction and predator abundance, most likely due to their short spawning periods and the reduced predatory pressures that occurred at dusk. Tides did not seem to be used exclusively as synchronizing cues by adult fishes for spawning. The influence of current speed in determining diel timing of spawning varied among species; some avoided spawning during low current speeds while the majority showed no clear response.
\end{abstract}

KEY WORDS: Spawning $\cdot$ Periodicity $\cdot$ Currents $\cdot$ Tides $\cdot$ Predation $\cdot$ Coral reef fishes

\section{INTRODUCTION}

Since the first descriptive observations of coral reef fish spawning (Randall 1961), many studies have described the behavior of pelagic-spawning reef fishes (for reviews see Thresher 1984, Robertson 1991, Sadovy 1996). There is a great variability in spawning behaviors among reef fish, and many different hypotheses have been formulated to explain their reproductive patterns (Robertson et al. 1990, Robertson 1991).

${ }^{*}$ Present address: AZTI, Technological Institute for Fisheries and Food, Department of Fisheries Resources, Txatxarramendi Ugartea z/g, 48395 Sukarrieta, Basque Country, Spain. E-mail: gsancho@azti.es
However there has been a clear lack of experimental studies designed to test these hypotheses (Shapiro et al. 1988, Robertson 1991).

One of the most variable and least understood aspects of reef fish reproduction is the diel pattern of spawning. Coral reef fish seem to follow 2 main short rhythms for spawning: diel and tidal. The relative importance of these 2 environmental cues (time of day and tides) varies among species, and between different locations within a single species. Some species spawn at a specific time of the day which can vary from early morning to after sunset, thus exhibiting a circadian rhythm (Robertson \& Hoffman 1977, Lobel 1978, Robertson \& Warner 1978, Warner \& Robertson 1978, Kuwamura 1981, Robertson 1982, Thresher 1982, Clavijo 1983, Lobel \& Neudecker 1985, Thresher \& 
Brothers 1985, Colin \& Clavijo 1988, Myrberg et al. 1989, Colin \& Bell 1991, Shibuno et al. 1993, van Rooij et al. 1996). In locations with strong tidal flows, a circatidal rhythm may overlap a circadian rhythm in certain species: spawning may occur at a specific time of the day, but only if the water flow will sweep propagules away from the reef (Randall 1961, Robertson \& Hoffman 1977, Johannes 1978, Lobel 1978, Thresher 1979, Kuwamura 1981, Tribble 1982, Warner 1982, Robertson 1983, Ross 1983, Bell \& Colin 1986, Moyer 1989, Colin \& Bell 1991). Fishes of the same species can also have different spawning rhythms in different locations of the same reef system, following circatidal rhythms at a reef edge and circadian rhythms at locations within a lagoon, where no currents off the reef exist (Robertson 1983, Colin \& Bell 1991). Also reef fish at a specific location can have a circatidal spawning rhythm during certain part of the year and a circadian spawning rhythm during the rest of the spawning season (Tribble 1982). These observations indicate that certain decision mechanisms utilized by reef fish to establish diel spawning patterns are plastic and influenced by local environmental conditions (van Rooij et al. 1996, Warner 1997), possibly in a similar way as occurs in intertidal crabs (Morgan \& Christy 1994, Morgan 1996).

Several different hypotheses have been proposed to explain the variety of diel and tidal spawning patterns observed in reef fish. Johannes (1978) proposed that the avoidance of short-term predation on eggs over reef structures is the determining factor of the spawning behavior. He suggested that spawning occurs at times of maximum current speeds in a direction away from the reef environment to minimize benthic predation of propagules, creating a circatidal spawning rhythm in locations where currents are tidally controlled. Barlow (1981) proposed that coral reef fish select times for spawning to maximize egg transport away from their natal reef areas, and that this behavior is adaptive because of the patchiness in availability of adult habitats. At spawning locations across a reef edge with tidally driven circulation, the onset of outflowing currents is generally believed to produce the maximum dispersal of eggs away from the reef. Colin \& Clavijo (1988) proposed that tides are used as a cue for adults to synchronize spawning, in order to reduce the overall time spent in reproductive activities. They suggested the timing of reproduction is independent of the survivorship and dispersal of eggs and larvae. Predation risks on the adult spawners and eggs have also been proposed as a way of explaining diel spawning patterns of reef fishes (Robertson \& Hoffman 1977, Johannes 1978, Lobel 1978, Thresher 1984, Robertson 1991), which should be risk-minimizing responses to feeding cycles of predatory fishes.
In spite of the abundance of explanatory hypotheses concerning diel spawning cycles of reef fishes, few studies have tested these hypotheses experimentally (Shapiro et al. 1988). Only the maximum dispersal hypothesis (Barlow 1981) has been tested for reef fishes in the field (Appeldoorn et al. 1994, Hensley et al. 1994): a comparison of estimated transport distances of eggs between spawning and non-spawning times and locations revealed no clear evidence that spawning behavior of Thalassoma bifasciatum (Labridae) ensures maximum transport of propagules away from the natal reefs.

Based on the previous hypotheses regarding the importance of water flow, use of tides and predation in establishing diel spawning times, the following predictions can be made:

1. Use of tidal currents for maximum dispersal of larvae. Fish should spawn at the onset of an outflowing current to maximize dispersal away from spawning grounds (Barlow 1981). A short spawning period after the reversal of tidal currents away from the reef would ensure long distance transport for most of the propagules.

2. Use of currents to minimize benthic predation on eggs. Reduction of benthic egg predation can potentially occur under different environmental conditions, leading to the subsequent predictions: (a) fish should preferentially spawn in outflowing currents that carry propagules away from benthic predators; (b) fish should spawn at times when currents are fastest, to reduce the time that propagules spend exposed to benthic predators; and (c) daytime-spawning species are more likely to use currents to minimize egg predation than dusk spawners. Dusk-spawning species generally have a very short diel spawning window (Thresher 1984), and their timing of egg release seems strongly influenced by light intensity levels (Myrberg et al. 1989). Dusk-spawning species are expected to be less likely to delay spawning when water flow conditions are inappropriate than daytime spawners.

3. Use of tides as a synchronization cue by adults. The use of tides as timing cues to synchronize the reproductive activities of fishes should lead to aggregation of conspecifics at spawning sites shortly after the moment of high or low tide (Colin \& Clavijo 1988). The timing of these aggregations should occur independently of the existing currents at the spawning site.

4. Risk of predation of adults. Since piscivores primarily attack fishes during their spawning ascent (Moyer 1987, Sancho et al. 2000), potential prey should show reduced spawning intensity activities during periods of high predatory activity.

To evaluate the above hypotheses, detailed measurements of current regimes at spawning sites are imperative (Shapiro et al. 1988). From the few studies 
that have measured currents at spawning grounds, a positive correlation between current speed and spawning activity has been described over daily (Hunt von Herbing \& Hunte 1991) and seasonal periods (Appeldoorn et al. 1994) for Thalassoma bifasciatum. In contrast, currents did not seem to influence timing of spawning of Epinephelus striatus (Serranidae), but the sampling period of the current speed measurements was not specified (Colin 1995). Predatory risk reduction hypotheses cannot be evaluated effectively as information on predator diel activity patterns at spawning sites is lacking (Robertson 1991).

In the present paper we compare observations of abundance and spawning intensity of 11 reef fish species with detailed measurements of current direction, current speed, time of day, tides and abundance of predators. We observed 11 species at the same spawning site to assess interspecific variability in spawning patterns under the same set of environmental conditions, and in this way to test specific predictions based on the characteristics of the different spawning species.

\section{METHODS}

Data collection. Reef fish spawning was monitored at 2 aggregation sites on Johnston Atoll (Central Pacific). This small and isolated atoll has a maximum width of $20 \mathrm{~km}$ and a reef crest only along its N-NW edge (Fig. 1). One of the spawning sites (Mustin's Gap) was the only significant channel that intersected the reef crest. It was approximately $28 \mathrm{~m}$ wide and $75 \mathrm{~m}$ long, with an average depth of $4.5 \mathrm{~m}$. The substrate consisted of a mix of live tabular coral formations

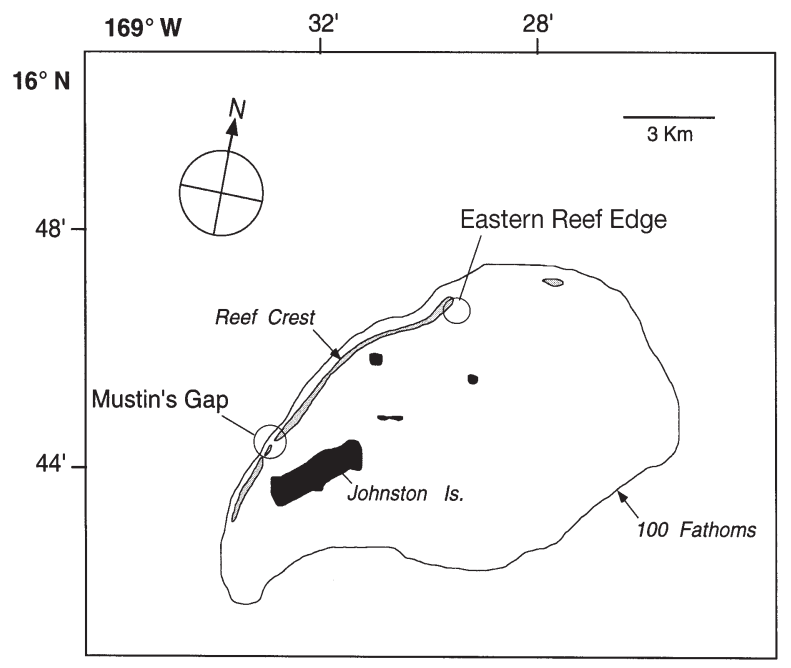

Fig. 1. Map of Johnston Atoll with the locations of the 2 spawning aggregations sites sampled in this study: Mustin's Gap and Eastern Reef Edge
(Acropora spp.), large dead coral boulders and fine coral rubble. The second spawning site (Eastern Reef Edge) was located inside the NE edge of the reef crest. It was a back reef location with an average depth of $4.5 \mathrm{~m}$. The substrate consisted of dispersed live tabular coral formations and coral rubble.

Within each spawning site, a smaller representative sampling area was established to measure fish abundance and spawning intensity. At Mustin's Gap the sampling area consisted of a $170 \mathrm{~m}^{2}$ rectangle located in the outer part of the reef channel over a mixed substrate of live tabular coral formations and large dead coral boulders. At the Eastern Reef Edge the sampling area was a $40 \mathrm{~m}^{2}$ tabular coral formation surrounded by coral rubble fields.

Current velocities and tidal heights were measured at both spawning sites with S-4 current meters (S4 InterOcean, San Diego), mounted on PVC tripods at a height of $1.5 \mathrm{~m}$ above the substrate. Their location was fixed inside both sampling areas. Current speed, direction and hydrostatic pressure were recorded every 15 min (average of 240 burst samples over a period of $2 \mathrm{~min})$.

Observations while diving with SCUBA were always done by the same person (G. Sancho) to reduce interobserver sampling bias. The diver's recording position was kept constant at both spawning grounds (always lying on the bottom and $5 \mathrm{~m}$ away from the edge of the sampling area). No modification of spawning or predatory behavior because of diver presence were detected, and fish would on occasion spawn only a few centimeters away from the observer. No fish were speared at the spawning sites during the observation season. Sampling was done in 1994 and 1995 during the months of April and May, coinciding with the peak spawning season at Johnston Atoll (G.S. \& P.S.L. unpubl. data). During 1994, 82 dives (105 h) were completed at Mustin's Gap from dawn though dusk, to quantify diel periodicity in spawning. In 1995, 92 dives (86 h) were made at Mustin's Gap, with early afternoon (13:00 through 16:30 h) and dusk (19:00 through 20:00 h) dives attempted on alternate days. High surf across the reef crest sometimes made it impossible to dive at Mustin's Gap, causing some breaks in the data series. During 1995 at the Eastern Reef Edge 9 dives $(14 \mathrm{~h})$ were done in the early afternoon (13:00 through 14:30 h), from 15 to 27 May.

Daytime observations were 30 min long, taken every hour. Dusk observations started at 19:00 h and usually continued past the time of sunset, when spawning activity had ceased completely. The total number of spawning rushes observed inside the sampling areas was annotated every minute, along with the spawning behavior employed in each rush: pair spawn (female and male), pair spawn with a streaker male (female and 2 
males) or group spawn (female and more than 2 males). This procedure allowed the quantification of intense spawning bouts typical of group-spawning species. The total number of spawning fish present at the sampling site was estimated at the beginning and end of each 30-min spawning count. Only fishes exhibiting spawning-related behaviors like courting, milling or bobbing (Meyer 1977, Moyer \& Yogo 1982) were counted.

All pelagic-spawning species were recorded (34 species), but in this study we only used data from 11 of the most active spawners: Parupeneus bifasciatus and Parupeneus multifasciatus (Mullidae); Chaetodon unimaculatus (Chaetodontidae); Cheilinus unifasciatus, Coris gaimard and Epibulus insidiator (Labridae); Chlorurus sordidus (Scaridae); Acanthurus nigroris, Ctenochaetus strigosus and Zebrasoma flavescens (Acanthuridae); and Ostracion meleagris (Ostraciidae). Spawning occurred at various times during the day, with some species spawning mostly in groups and others in pairs (Table 1).

The presence or absence of piscivorous fish over the spawning grounds in addition to any predation events on adult spawners were recorded every minute during the 30 -min observation periods. The 2 most abundant piscivorous species at the spawning grounds were Caranx melampygus (Carangidae) and Aphareus furca (Lutjanidae).

Data analyses. Multifactorial analyses were used to study the correlation of fish abundance, total number of spawns and spawning intensity (spawns per fish) with various independent environmental variables: time of day, tides, current velocity and presence of piscivores. The data set included afternoon observations from 1995 and dusk observations from both 1994 and 1995.

A stepwise multiple regression model was used with group-spawning species and dusk pair-spawning species, since they had relatively high spawning rates. Quadratic terms were included in the model for the independent variables of current velocity and tide to analyze for second order polynomic relations between the dependent and independent variables. For each dependent variable an initial multiple regression model was calculated including all independent variables, and significant variables were identified through a backwards elimination method $(p<0.05$ significance level).

Daytime pair-spawning species spawned infrequently, leading to many 15 -min periods with no spawning observations or only 1 or 2 spawning observations. These data were transformed into binomial data sets, and a logistic model based on a logistic transformation of binomial data was calculated to compare spawning rates with independent variables (Collett 1991). A backwards elimination method was used to simplify the model and identify the significant independent variables ( $\mathrm{p}<0.05$ significance level).

Raw spawning data collected every minute were transformed into number of spawns per 15-min interval. This time period was long enough to detect short synchronized spawning bouts typical of some groupspawning species (Colin \& Clavijo 1978, Robertson

Table 1. Spawning behavior of 11 reef fishes at the spawning aggregations of Johnston Atoll. Total number of spawns observed during each sampling year; spawning behavior: $\mathrm{G}=$ group spawning, $\mathrm{P}=$ pair spawning, $\mathrm{G}>\mathrm{P}=$ mostly group spawning with some pair spawning; mating system: $\mathrm{MON}=$ monogamy, $\mathrm{MT}=$ male territory, $\mathrm{PRO}=$ promiscuity, HAR = haremic; predation on adults: attacks on spawners by Caranx melampygus or Aphareus furca; predation on eggs: attacks on eggs by Melichthys niger or Melichthys vidua; time spawning: $1 \mathrm{~h}$ period when the median value of spawning times occurred during 1994; sunset was between 19:32 and 19:46 h

\begin{tabular}{|c|c|c|c|c|c|c|c|c|}
\hline \multirow[t]{2}{*}{ Family } & \multirow[t]{2}{*}{ Species } & \multicolumn{2}{|c|}{ No. of spawns } & \multirow{2}{*}{$\begin{array}{l}\text { Spawning } \\
\text { behavior }\end{array}$} & \multirow{2}{*}{$\begin{array}{l}\text { Mating } \\
\text { system }\end{array}$} & \multicolumn{2}{|c|}{ Predation on: } & \multirow{2}{*}{$\begin{array}{c}\text { Time spawning } \\
\text { (median) }\end{array}$} \\
\hline & & 1994 & 1995 & & & Adults & Eggs & \\
\hline \multirow{2}{*}{$\begin{array}{l}\text { Mullidae } \\
\text { (goatfish) }\end{array}$} & Parupeneus bifasciatus & 15 & 44 & $\mathrm{P}$ & MT & No & No & 19:00-20:00 \\
\hline & Parupeneus multifasciatus & 36 & 50 & $\mathrm{P}$ & $\mathrm{MT}$ & No & Yes & $19: 00-20: 00$ \\
\hline $\begin{array}{l}\text { Chaetodontidae } \\
\text { (butterflyfish) }\end{array}$ & Chaetodon unimaculatus & 3 & 14 & $\mathrm{P}$ & $\mathrm{MON}$ & No & No & 19:00-20:00 \\
\hline \multirow{3}{*}{$\begin{array}{l}\text { Labridae } \\
\text { (wrasses) }\end{array}$} & Cheilinus unifasciatus & 24 & 69 & $\mathrm{P}$ & MT & No & No & $17: 00-18: 00$ \\
\hline & Coris gaimard & 39 & 66 & $\mathrm{P}$ & $\mathrm{MT}$ & No & No & $16: 00-17: 00$ \\
\hline & Epibulus insidiator & 41 & 21 & $\mathrm{P}$ & $\mathrm{MT}$ & No & No & $14: 00-15: 00$ \\
\hline $\begin{array}{l}\text { Scaridae } \\
\text { (parrotfish) }\end{array}$ & Chlorurus sordidus & 1433 & 2654 & $\mathrm{G}>\mathrm{P}$ & $\mathrm{PRO}, \mathrm{MT}$ & Yes & Yes & $14: 00-15: 00$ \\
\hline \multirow{3}{*}{$\begin{array}{l}\text { Acanthuridae } \\
\text { (surgeonfish) }\end{array}$} & Acanthurus nigroris & 1520 & 1981 & G & PRO & Yes & Yes & $16: 00-17: 00$ \\
\hline & Ctenochaetus strigosus & 339 & 531 & $G>P$ & PRO & Yes & No & $18: 00-19: 00$ \\
\hline & Zebrasoma flavescens & 504 & 479 & G & PRO & Yes & No & $17: 00-16: 00$ \\
\hline $\begin{array}{l}\text { Ostraciidae } \\
\text { (trunkfish) }\end{array}$ & Ostracion meleagris & 85 & 13 & $\mathrm{P}$ & HAR? & No & Yes & 19:00-20:00 \\
\hline
\end{tabular}


1983), and allowed spawning data to be compared with the water flow measurements. For group-spawning species, the spawning intensity (number of spawns per individual fish) was calculated by dividing the 15-min spawning measurements by the number of fish present at the sampling site. Data transformations for multifactorial analyses of the 3 dependent variables were as follows:

1. Fish abundance. Data were only available for group spawners. No accurate abundance counts could be obtained for pair-spawning species due to cryptic behavior of certain females, high degree of mobility of spawning pairs and lack of long pre-spawning courtships. For group spawners there was high daily variability in fish abundance, which complicated direct comparisons between abundance values from different days. To solve this problem, abundance data from different observation periods were standardized to maximum daily abundance values, creating a data set that varied between 0 and 1 . These data were normalized by arcsine transformation (Sokal \& Rohlf 1995) for multiple regression analyses. Independent variables used in the multifactorial analysis of fish abundance were current direction, time of day and tides. All these variables have been previously described as cues synchronizing specific Indo-Pacific reef fish migrations to spawning grounds: light intensity (Myrberg et al. 1989), tidal cycles (Robertson 1983, Colin \& Bell 1991) and reversals in current direction (Moyer 1989). Current speed and predator abundance at the spawning sites cannot be detected from far away, and therefore were not considered as potential causal factors for fish migration.

2. Number of spawns. In those species for which a regular tidal spawning periodicity was detected, only spawning data from the maximum spawning tidal period (flood tide or ebb tide, depending on the species) were used in the analysis. To reduce the influence of days with low spawning activity in the multifactorial analyses, for non-tidal, group-spawning species only those dates accounting for $85 \%$ of total spawning output were included, while for non-tidal, pair spawners only those days with at least 1 spawn were included. To standardize spawning effort among days, spawning values were divided by daily maximum spawning values and then arcsine transformed. Independent variables used were time of day, current velocity, and abundance of Caranx melampygus and Aphareus furca.

3. Spawning intensity. Defined as the number of spawns per fish present, spawning intensity was only available for group-spawning species, since accurate abundance estimates could not be obtained for pairspawning species. All samples were used except those days when no fish were present at the spawning grounds. Normalization of these data was done through a logarithmic transformation (Sokal \& Rohlf 1995). Independent variables used were time of day, current velocity and abundance of Caranx melampygus and Aphareus furca. This analysis was performed to study behavioral choices in spawning times by the fish present at the spawning grounds. Potential causes leading to delays of spawning were (a) perceived risk of reduced larval survivorship (affected by time of day and current velocity) and (b) predation risks (affected by predator presence and time of day). As hydrostatic pressure hypothetically is not believed to influence survivorship of adults or larvae, tidal height values were not included in spawning intensity analyses.

Data on environmental variables at the spawning site were also subjected to various transformations. Current speed and direction data recorded by the current meters every 15 min were transformed into current velocities, with positive values indicating outgoing flows with respect to the reef crest (from the lagoon into open waters) and negative values representing currents flowing into the lagoon. To compare daily spawning output values with current speed, mean current speed was calculated for each day by averaging all the 15-min values from 13:00 to $16: 30 \mathrm{~h}$ for midday spawners, and from 19:00 to 20:00 h for dusk spawners. The time of day when spawning observations were made was standardized as the number of minutes from sunset (negative values express time before sunset, positive ones indicate time after sunset). Exact times for high and low tides at Johnston Atoll were obtained using Worldtide software (Micronautics, Rockport, ME, USA), since tidal heights recorded on site with current meters were nearly identical to those predicted by NOAA tables (G.S. pers. obs.). Spawning times with respect to tides were expressed as number of minutes from the closest low tide. Negative values indicate that spawning occurred before low tide (ebb tide), and positive values represent spawning observations taking place after low tide (flood tide). Measurements of piscivore presence (presence/absence during 1-min periods) were expressed as the percentage of time predators were present over the spawning sampling site per 15-min interval.

Correlations among some independent variables precluded their joint inclusion into the multifactorial analyses. Abundance of the predators Caranx melampygus and Aphareus furca covaried positively in dusk data sets $\left(R^{2}=0.552\right)$, so they were combined into 1 variable (presence of predators) by averaging the data from both species. Because current speed and tides covaried during midday data sets at both Mustin's Gap and Eastern Reef Edge these variables were never used simultaneously in multifactorial analyses.

To identify significant deviations within frequency distributions of fish abundance and number of spawns, 
Fig. 2. Current velocities and tidal heights at Mustin's Gap on 2 May 1995, representing a tidally influenced day. Dashed lines indicate the moments of high and low tides. Positive current velocity values represent outflowing directions, and negative represent inflowing ones (oriented perpendicularly relative to the reef crest)
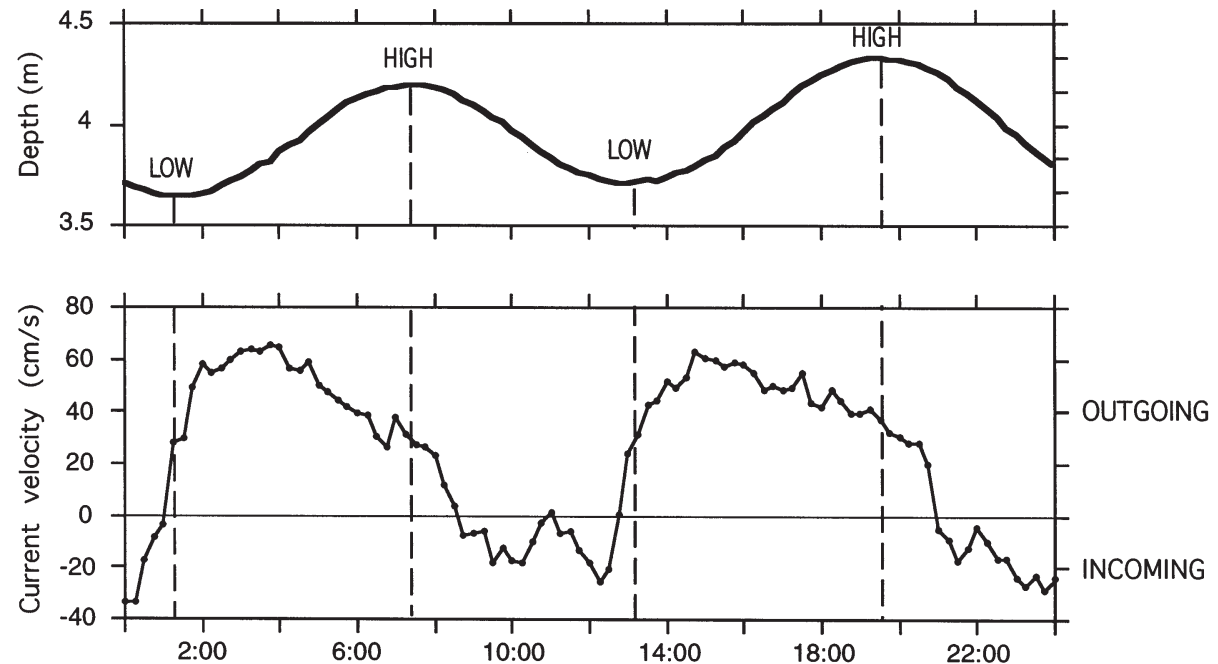

observed distributions were compared to expected distributions based on our sampling effort using $\chi^{2}$ tests for goodness-offit. Classes were chosen such that expected frequencies were never less than 2 (Miller 1986), and significance of departure from independence in single cells was evaluated by comparing individual residuals with a Bonferroni familywise error rate of 0.05 (Sokal \& Rohlf 1995).

\section{RESULTS}

\section{Water flow}

The main spawning site, Mustin's Gap, typically experienced tidally influenced semi-diurnal reversing flows (Fig. 2). Currents were coupled with the tides, with outgoing flows (water flowing from the lagoon into the ocean) during flood tides and incoming flows into the lagoon during ebb tides. Outflowing currents were, on average, faster than inflowing ones (averages of 38.5 and $14.2 \mathrm{~cm} \mathrm{~s}^{-1}$ respectively).

Fig. 3. Depth profile (A) and current velocities (B) representing a transition from tidally influenced currents to wave-influenced currents recorded at Mustin's Gap between 3 and 8 May 1995; depth profile (C) and current velocities (D) recorded at Eastern Reef Edge between 15 and 20 May 1995

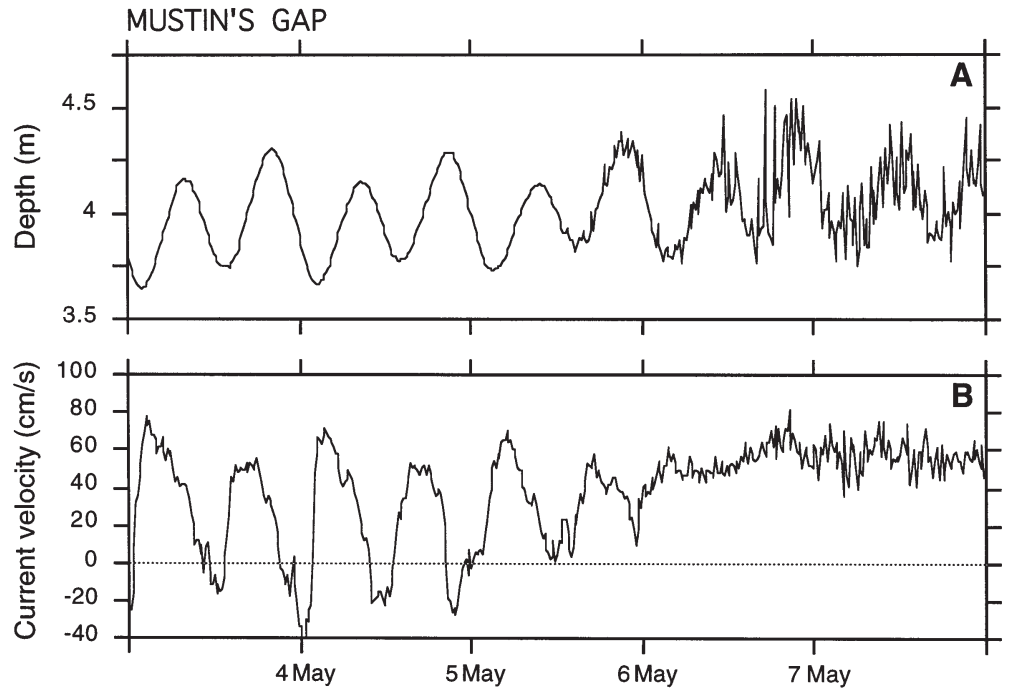

EASTERN REEF EDGE

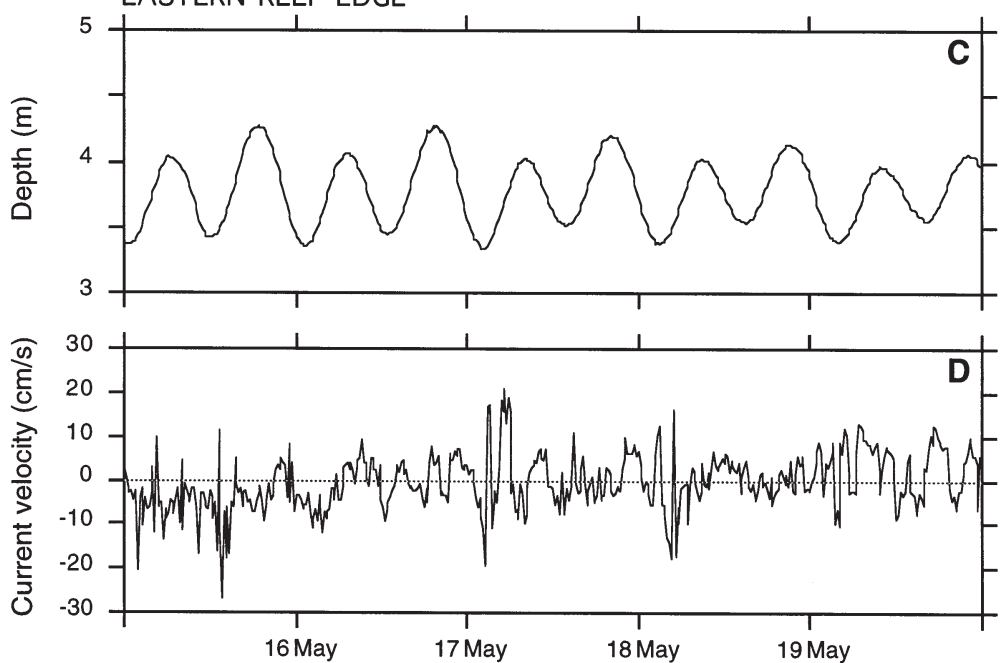



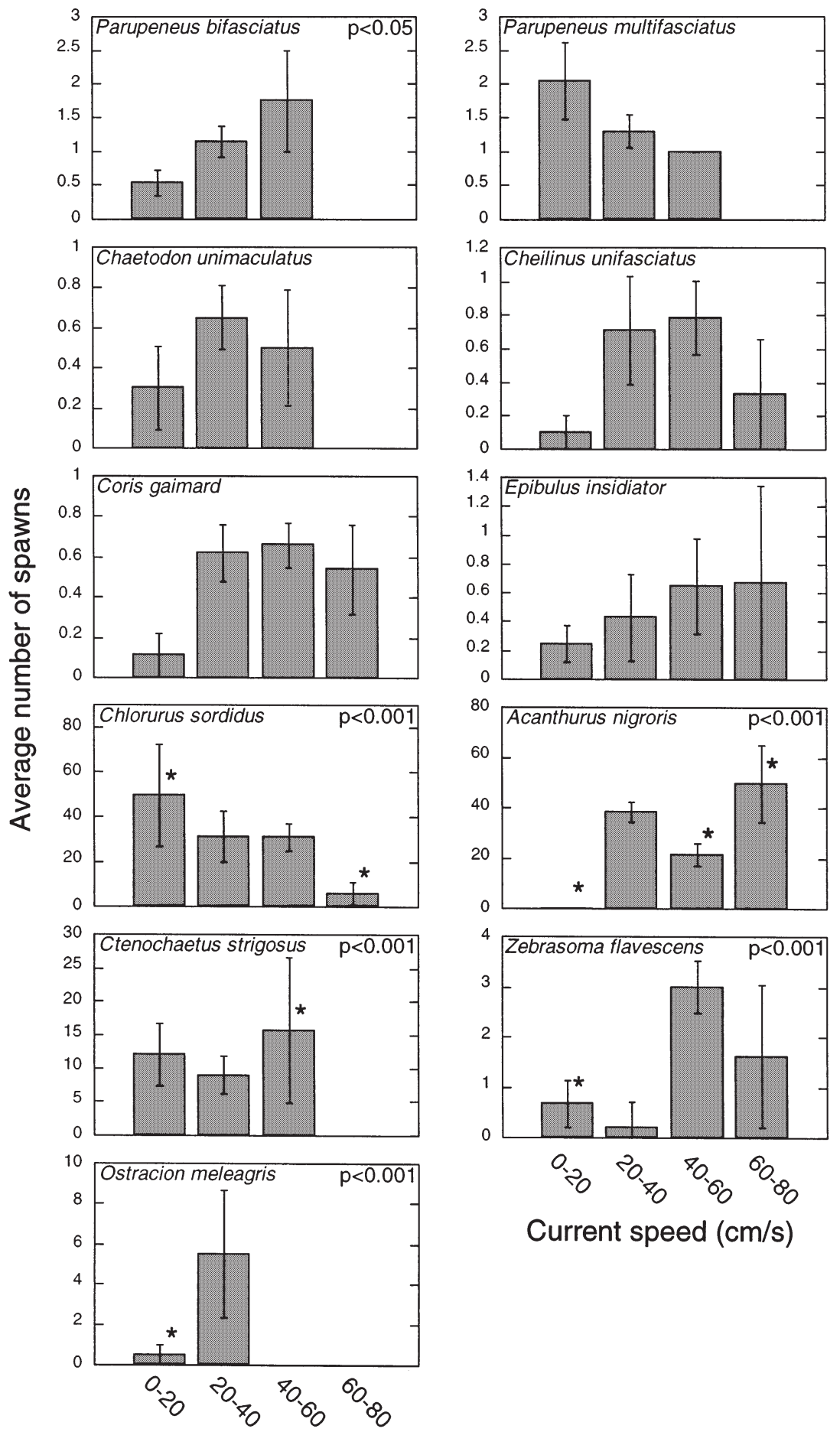

Current speed $(\mathrm{cm} / \mathrm{s})$

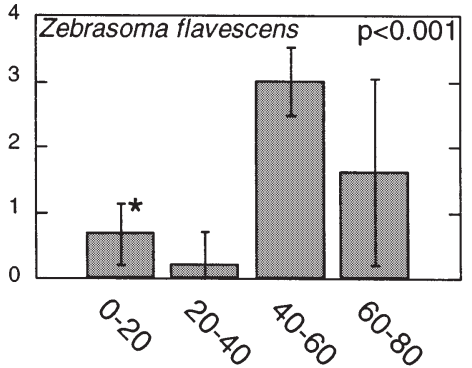

Current speed $(\mathrm{cm} / \mathrm{s})$

Fig. 4. Spawns according to different current speed categories. Spawning values are averages of 15 -min observations $( \pm \mathrm{SE})$. Data used in this analysis are from days when spawning occurred, and in the case of species that selected certain flow directions for spawning, only current speed data from flows in the preferred direction were included. Observed values are compared with a distribution based only on the sampling effort at different tidal times through a $\chi^{2}$-test; p-values are shown when significant. Asterisks indicate significance of $\chi^{2}$ residuals with a Bonferroni familywise error of 0.05

This semi-diurnal circulation across the reef crest was disrupted on occasions, becoming a unidirectional flow with uniform current speeds in an outward direction (Fig. 3A,B). These events occurred on days of high surf conditions (G.S. pers. obs.) and were tightly correlated with an increase in variability in the hydrostatic pressure profiles recorded by our current meters, probably due to large waves crossing over the moored current meter. In a 55-d current meter record (3 April to 27 May 1995), 36 of the days $(65.5 \%)$ showed bi-directional currents coupled with tides and 19 of the days (34.5\%) displayed fully unidirectional flows.

At Eastern Reef Edge, the flows were not as tightly coupled with the tides as in Mustin's Gap (Fig. 3C,D). Current direction was independent of tidal state, but highest current speeds usually occurred shortly after low tide. This relation between tides and water flow was confirmed by the negative correlation found in 768 simultaneous measurements of tidal height and current speed (Spearman's rank correlation: $\left.r_{s}=-0.27 ; \mathrm{p}<0.001\right)$. Average current speeds were similar for outflowing $\left(7.1 \mathrm{~cm} \mathrm{~s}^{-1}\right)$ and inflowing $\left(5.2 \mathrm{~cm} \mathrm{~s}^{-1}\right)$ currents at Eastern Reef Edge, and were much slower than at Mustin's Gap.

\section{Relation of spawning with water flow}

All 3 group-spawning species for which data were available (Chlorurus sordidus, Zebrasoma flavescens and Ctenochaetus strigosus) spawned more often during outflowing conditions than expected based solely on sampling effort $\left(\chi^{2}\right.$-test; $\left.\mathrm{p}<0.001\right)$. Spawning by Acanthurus nigroris was not analyzed, since no inflowing conditions were observed at Mustin's Gap during the early spawning season of this surgeonfish. Of the 7 pairspawning species, Cheilinus unifasciatus preferred outflowing conditions for spawning $\left(\chi^{2}\right.$-test; $\left.p<0.05\right)$, while 
A)
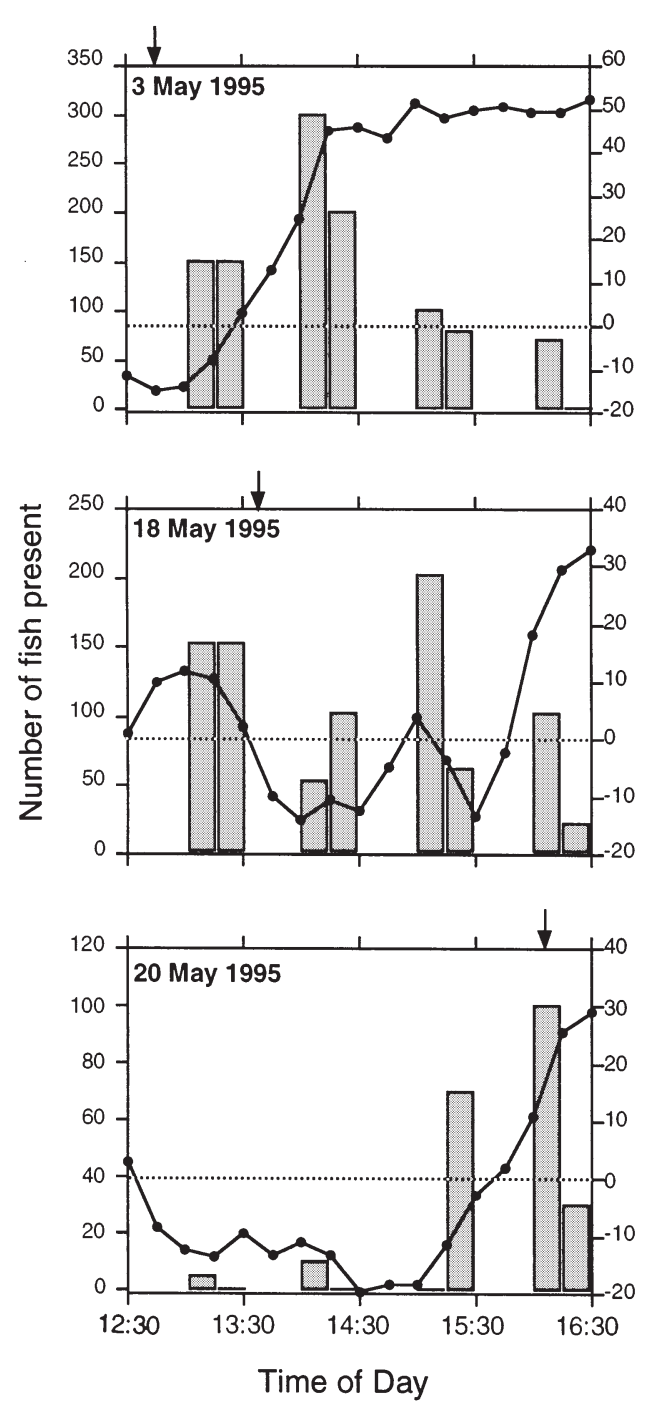

B)
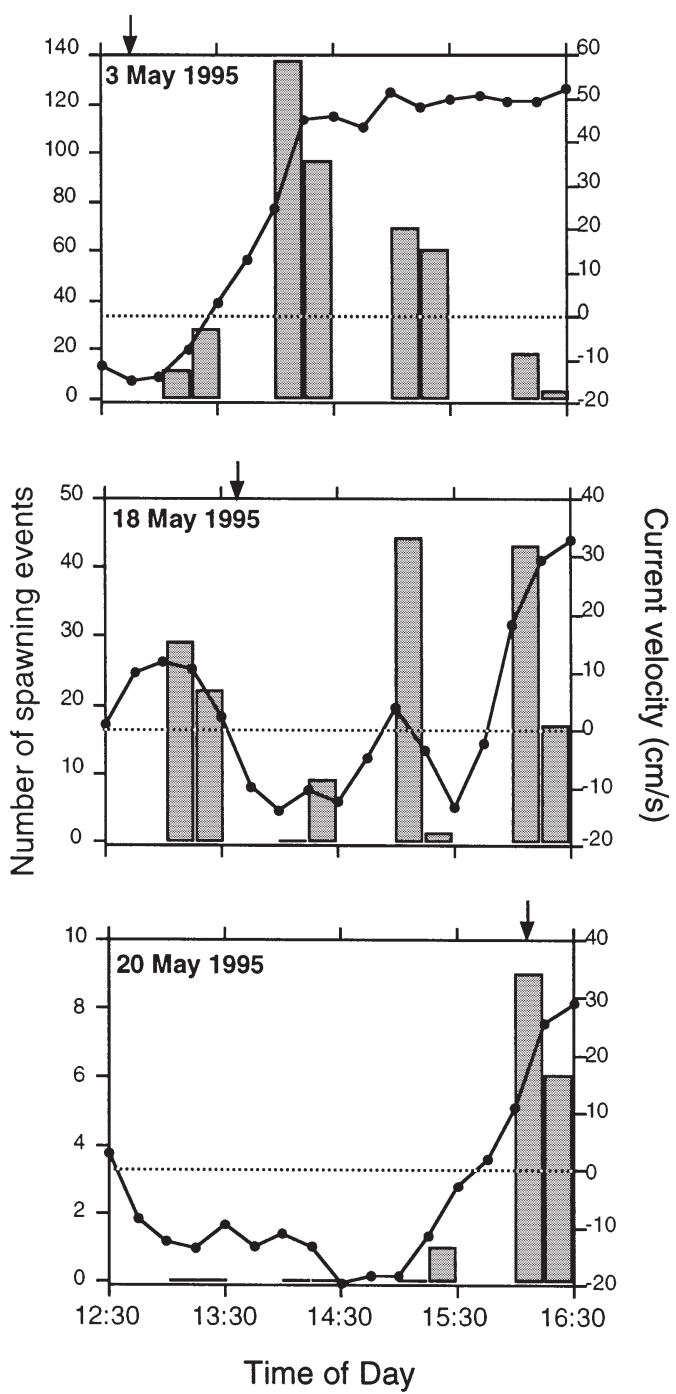

Fig. 5. Chlorurus sordidus. Abundance (A) and spawning sequences (B) at Mustin's Gap during days when current reversals occurred in 1995. Gray bars indicate number of fish present at spawning grounds or the number of spawns observed in 15-min counts. The black solid lines indicate the current velocities $\left(\mathrm{cm} \mathrm{s}^{-1}\right)$ recorded with the current meter (positive $=$ outflowing; negative $=$ inflowing). Horizontal dotted lines represent the change of current direction. The arrows on top of graphs indicate the exact time of low tide

Ostracion meleagris spawned preferentially during inflowing conditions $\left(\chi^{2}\right.$-test; $\left.\mathrm{p}<0.001\right)$. Chlorurus sordidus at Eastern Reef Edge spawning site also seemed to prefer inflowing conditions $\left(\chi^{2}\right.$-test; $\left.\mathrm{p}<0.001\right)$.

All 4 group-spawning species presented significantly different spawning distributions with respect to current speeds than expected distributions based solely on sampling effort (Fig. 4), but only 2 species (Acanthurus nigroris and Ctenochaetus strigosus) showed preferences towards the fastest current speeds. Of the 7 pair-spawning species, Ostracion meleagris selected the fastest inflowing currents on those days when they spawned, which never had cur- rent speeds faster than $40 \mathrm{~cm} \mathrm{~s}^{-1}$. Parupeneus bifasciatus seemed to increase spawning with faster currents, but the significance of this result should be considered cautiously due to low sample size (Miller 1986). The rest of the observed reef fish species did not select any specific speed categories for spawning (Fig. 4).

\section{Current reversal moments}

On a few occasions (3, 12, 18 and 20 May 1995) a reversal in current direction occurred while spawning observations were being recorded, allowing the study 
A)
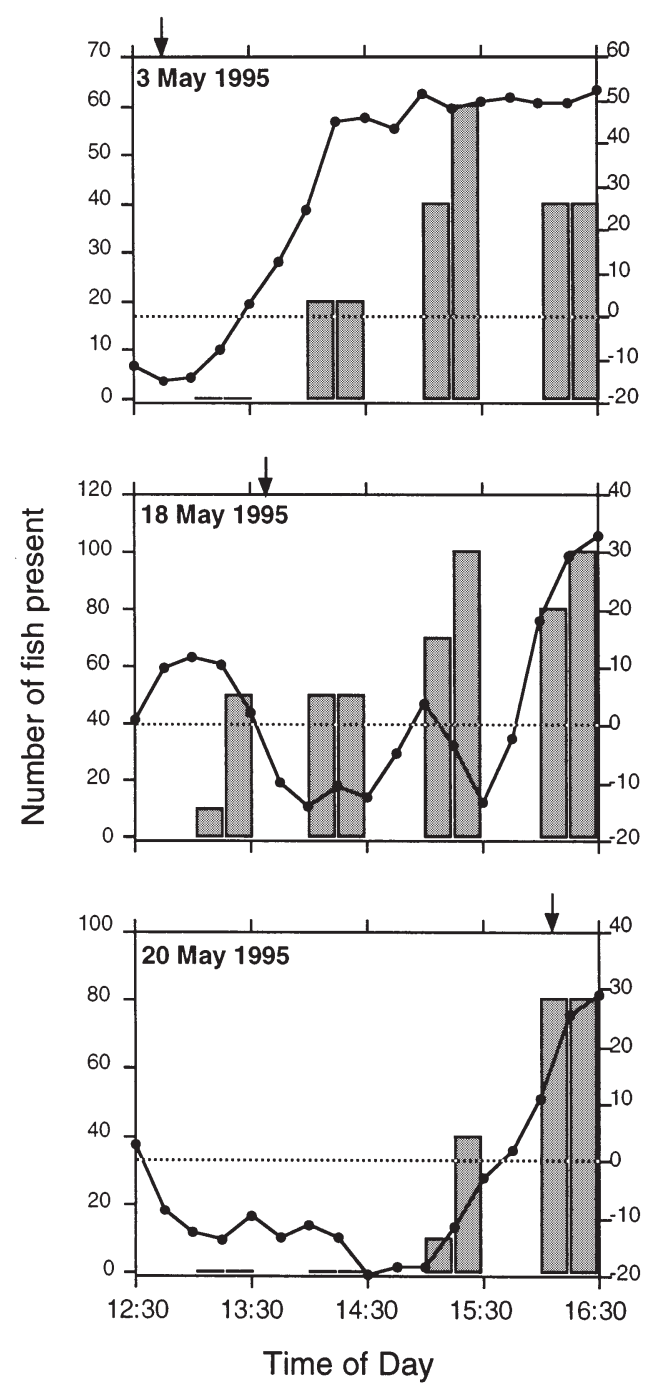

B)
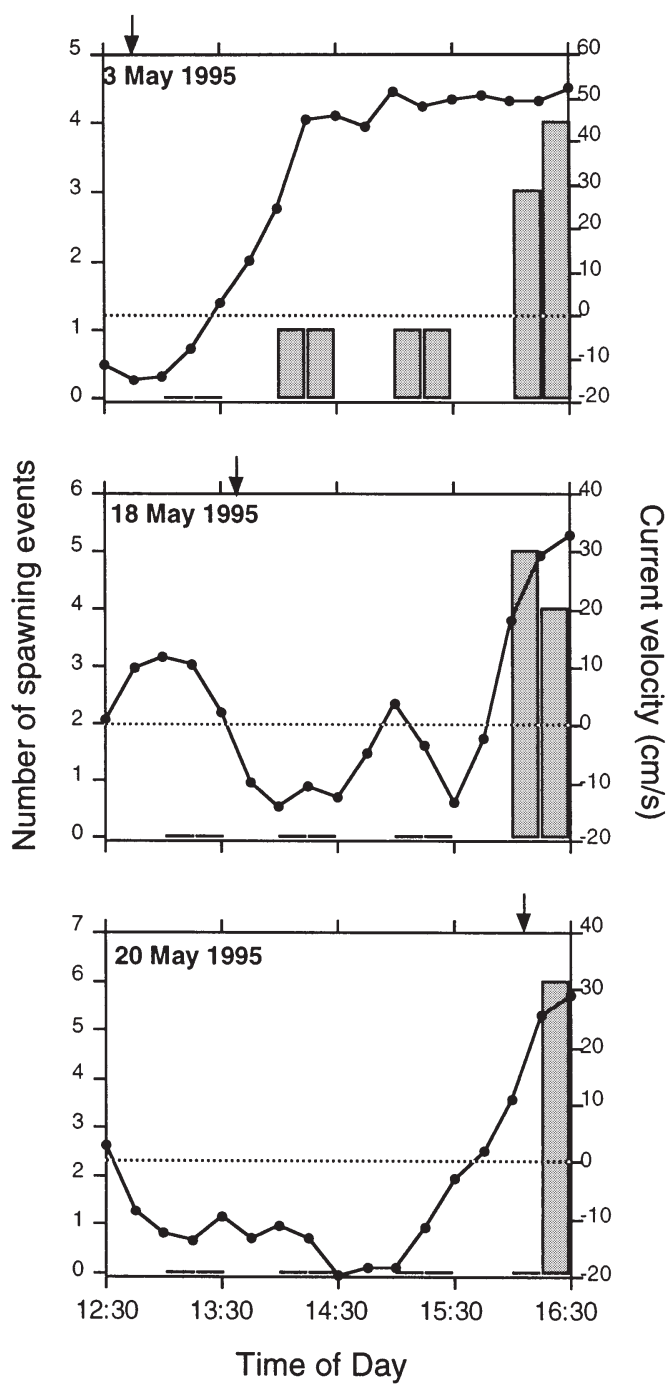

Fig. 6. Zebrasoma flavescens. Abundance (A) and spawning (B) sequences at Mustin's Gap during days when current reversals occurred in 1995. Details as in legend of Fig. 5

of behavioral responses by spawning fishes to this change in water flow. Overall, Chlorurus sordidus decreased in abundance with time during the afternoon and during moments of inflowing currents (Fig. 5A). During the moments of current reversal, fish did not leave the spawning grounds while inflowing conditions persisted, but interrupted their courting behaviors and resumed feeding behaviors, grazing algae off the substrate (G.S. pers. obs.). Subsequently these fish were not considered in the spawning fish censuses, which counted only fishes showing spawning-related behaviors. Spawning counts clearly showed that $C$. sordidus strongly avoided inflowing conditions for spawning. Fish delayed their spawning until the moment when currents reversed and become outflowing, showing a large spawning bout following the change in current direction (Fig. 5B). On 18 May 1995, fish spawned during the moments of weak outflowing currents $\left(3.9 \mathrm{~cm} \mathrm{~s}^{-1}\right)$, avoiding similarly weak inflowing currents $\left(3.4 \mathrm{~cm} \mathrm{~s}^{-1}\right)$.

The surgeonfish Zebrasoma flavescens showed an increase in presence and spawning as the afternoon progressed (Fig. 6A,B). Sudden decreases in fish abundance at the spawning grounds during changing currents (as detected in Chlorurus sordidus) did not occur, but surgeonfish did not move into the spawning grounds until currents started flowing outwards.

At dusk, changes in current direction only occurred once (12 May 1995). Ctenochaetus strigosus abundance seemed unaffected by the change in current 


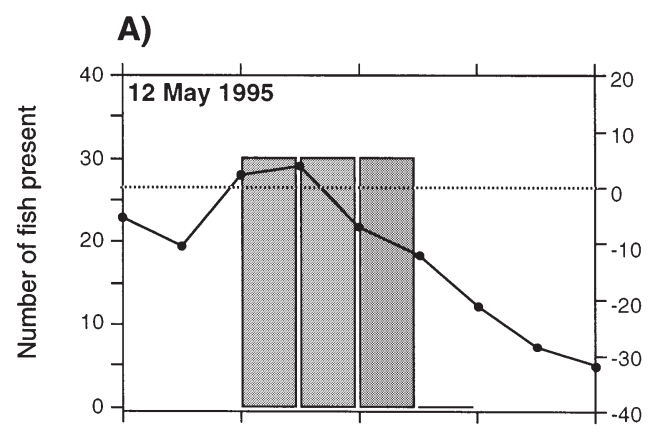

B)

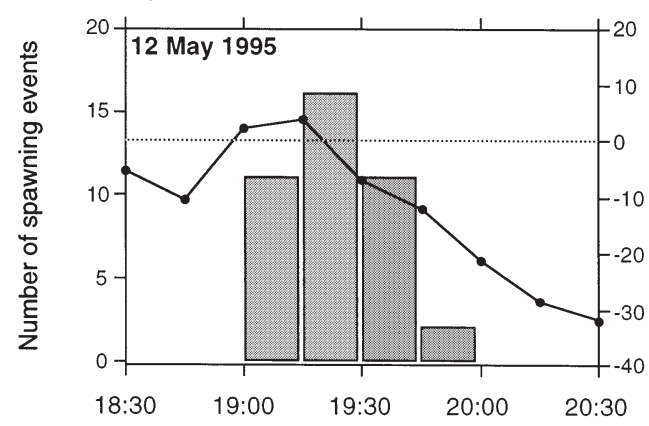

Fig. 7. Ctenochaetus strigosus. Abundance (A) and spawning sequences (B) at Mustin's Gap during 12 May 1995. Details as in legend of Fig. 5

direction, and the number of spawns observed was comparable among inflowing, outflowing and transitional periods (Fig. 7A,B). A decrease in abundance and spawning activity occurred late into the dusk period.

\section{Daily spawning patterns}

Daily spawning averages generally did not reflect the overall current intensity at the spawning site. When comparing the average daily number of spawns with the daily average current speed at Mustin's Gap using 1995 data, we only found significant correlations in 2 of the 11 species: Cheilinus unifasciatus spawned more on days with weak currents (Spearman's rank correlation: $\mathrm{r}_{\mathrm{s}}=-0.47$ ), while for Parupeneus bifasciatus daily average spawning was positively correlated with the average dusk current speed for a given day (Spearman's rank correlation: $\mathrm{r}_{\mathrm{s}}=0.69$ ).

The 2 most active group-spawning species had nonoverlapping spawning seasons during spring of 1995 : Acanthurus nigroris only spawned during the first $2 / 3$ of the month of April, while Chlorurus sordidus only had limited afternoon spawning activity. During the end of April and through May, A. nigroris ceased spawning and C. sordidus greatly increased their spawning activities. The observed seasonal spawning pattern of C. sordidus could be the result of a lunar spawning pattern with different spawning outputs during 2 consecutive lunar cycles and the short sampling period of this study. For this reason, in subsequent analyses only the data from the main spawning periods for $A$. nigroris and C. sordidus were used.

\section{Relation of fish abundance and spawning with tides}

All 4 group-spawning species had abundance distributions during tidal periods that were significantly different from those expected just from the sampling effort (Fig. 8A). Acanthurus nigroris had reduced abundance from $2 \mathrm{~h}$ before until the $1 \mathrm{~h}$ after low tide. The abundance of Chlorurus sordidus was high from $2 \mathrm{~h}$ before low tide until $5 \mathrm{~h}$ after it. Ctenochaetus strigosus showed 2 minor peaks in abundance occurring during the middle of the flood and ebb tides. Zebrasoma flavescens showed a broad peak in abundance at low tide and during the beginning of the flood tide, with a narrow abundance peak at the time of high tide. The tidal distribution of spawns for each groupspawning species was similar to their abundance distribution, and all were significantly different from expected distributions based solely on sampling effort (Fig. 8B)

At Eastern Reef Edge, the abundance of Chlorurus sordidus gradually increased during the last hours of ebb tide, peaking 1 to $3 \mathrm{~h}$ after low tide (Fig. 8A). Their spawning activity was almost exclusively concentrated during this 2-h period (Fig. 8B). Both abundance and spawning intensity varied over time and differed significantly from distributions based solely on sampling effort. These results from Eastern Reef Edge are similar to the results from Mustin's Gap, even though spawning activities took place over a shorter period of time at Eastern Reef Edge.

Distributions of spawns with respect to tidal times for pair-spawning species were significantly different from a tidally homogeneous distribution for 3 species (Chaetodon unimaculatus, Cheilinus unifasciatus and Ostracion meleagris), and did not differ significantly for the other 4 species (Fig. 9).

The differential allocation of spawns to either ebb or flood tides was established by comparing our observed spawning distributions with those expected based exclusively on the sampling effort ( $\chi^{2}$-test): Acanthurus nigroris ( $\mathrm{p}<0.001)$, Chlorurus sordidus $(\mathrm{p}<0.001)$, Ctenochaetus strigosus $(\mathrm{p}<0.05)$, Epibulus insidiator $(\mathrm{p}<0.05)$, Cheilinus unimaculatus $(\mathrm{p}<0.005)$ and Parupeneus bifasciatus $(\mathrm{p}<0.001)$ spawned signifi- 
A)
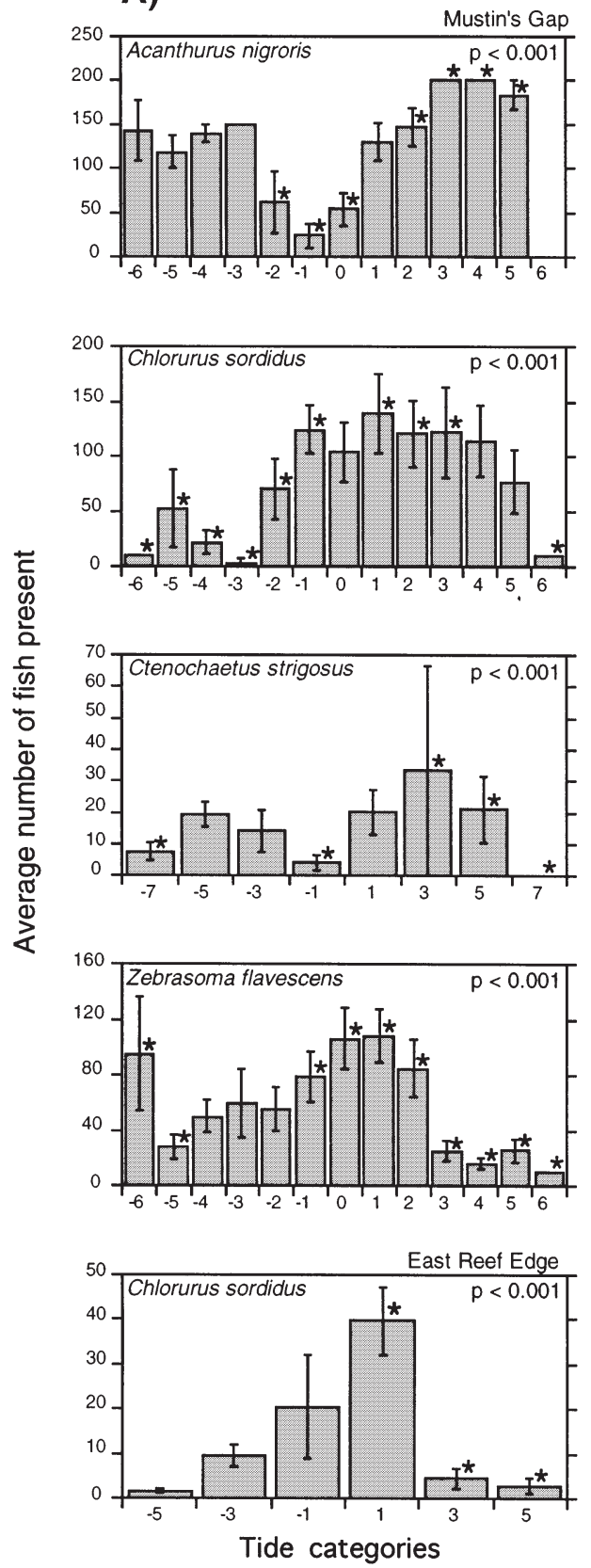

B)
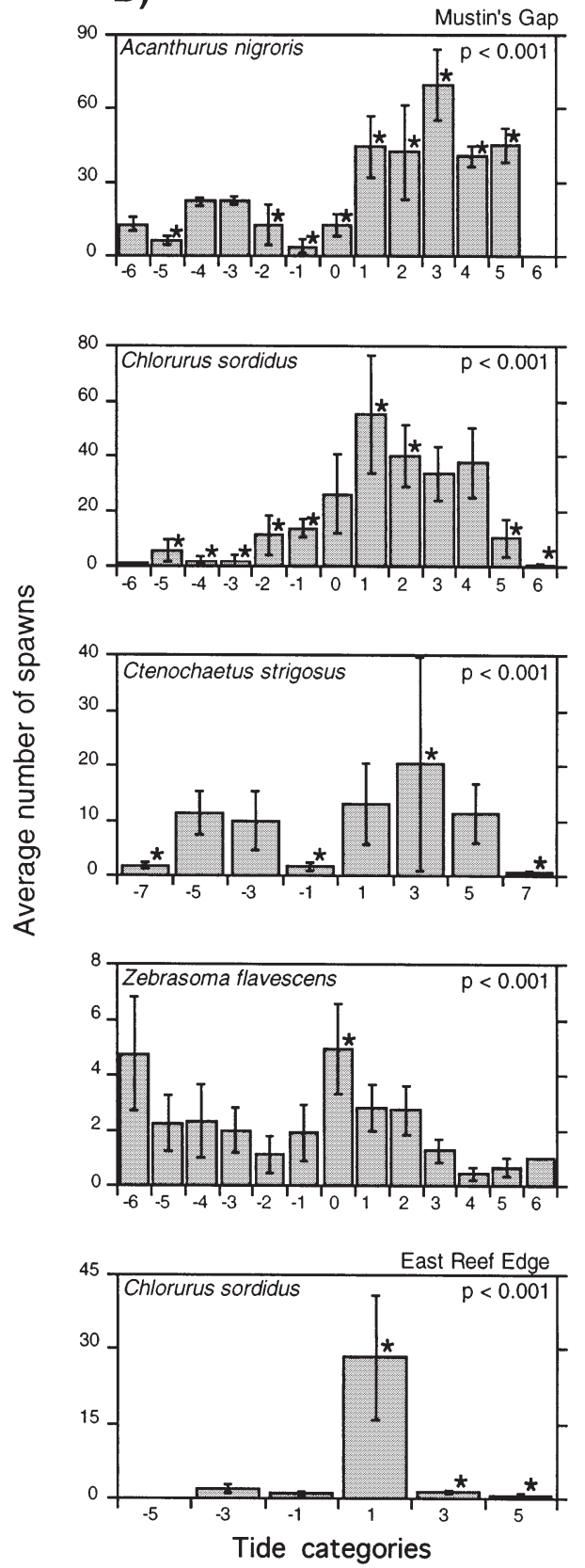

Fig. 8. Fish abundance (A) and spawns (B) of group-spawning species at different tidal times. Abundance and spawning values are averages of 15 -min observations $( \pm \mathrm{SE}$ ) pooled from a total of 140 measurements for afternoon spawners, and 72 for dusk spawners. Tidal categories express hours from low tide. Negative tidal category values indicate number of hours before low tide (ebb tides) and positive values indicate hours after low (flood tides). The top 8 graphs correspond to Mustin's Gap, the bottom 2 to Eastern Reef Edge. Observed values are compared with a distribution based only on the sampling effort at different tidal times through a $\chi^{2}$-test; p-values are shown when significant. Asterisks indicate significance of $\chi^{2}$ residuals with a Bonferroni familywise error of 0.05

cantly more often during flood tides, and Ostracion meleagris was the only species to preferentially use ebb tide for spawning $(\mathrm{p}<0.001)$. The other 4 species showed no difference in spawning between flood and ebb.

\section{Multifactorial analyses}

Some of the environmental variables explained a portion of the variability in abundance of groupspawning species at Mustin's Gap (Table 2). Abun- 

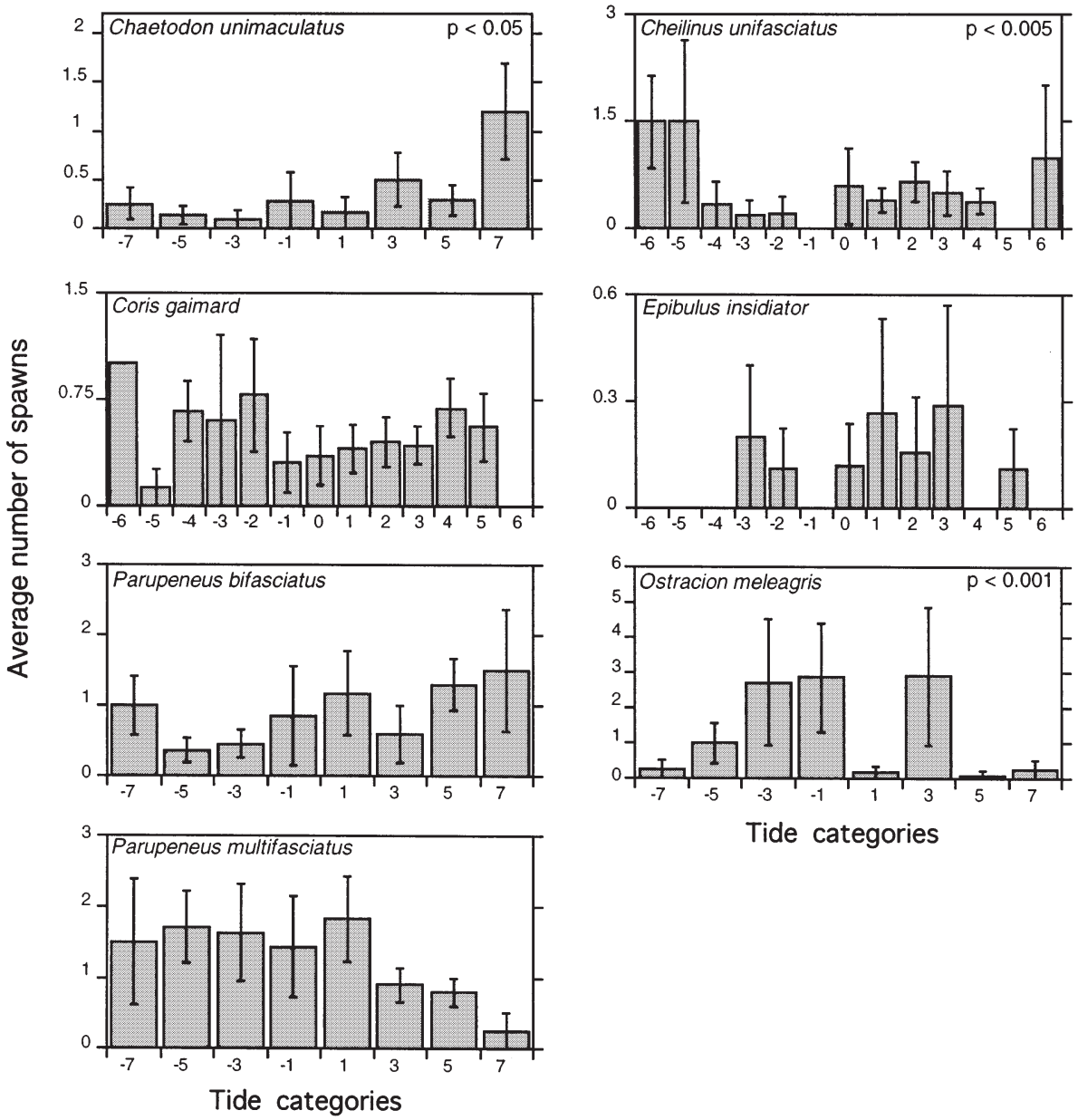

Tide categories

Fig. 9. Spawns of pair-spawning species at different tidal times. Spawning values are averages of 15 -min observations $( \pm$ SE) pooled from a total of 140 measurements for afternoon spawners, and 72 measurements for dusk spawners. Other details as in legend of Fig. 8; all graphs are from Mustin's Gap. Asterisks indicate significance of $\chi^{2}$ residuals with a Bonferroni familywise error of 0.05

dance values of all 4 group-spawning species were significantly correlated with a specific time of the day, and abundance of 3 species peaked during flood tides. No incoming current flows were ever detected during the spawning season of Acanthurus nigroris, so assessment of the influence of current direction on this species' behavior was not possible. But of the other 3 species, Chlorurus sordidus and Zebrasoma flavescens increased in abundance during outflowing currents and Ctenochaetus strigosus increased during inflowing currents.

The multifactorial analyses of the total number of spawns observed in group spawners indicated a high interspecific variability of responses (Table 3). All 4 group-spawning species showed a significant correlation of the distribution of spawns with a particular time of day. Spawns for 2 species (Acanthurus nigroris and Ctenochaetus strigosus) were significantly correlated only with time of day, and none of the other variables.
Number of spawns from the other 2 species were negatively correlated with abundance of a single predatory species, and showed different relations with current velocity. The number of spawns by Chlorurus sordidus peaked during moderate outflowing currents (quadratic relation), while Zebrasoma flavescens showed an increase in spawning activity at high outflowing currents (linear relation).

Analysis of spawning intensity in Acanthurus nigroris showed a weak correlation with environmental variables, but an increase in spawning activities late in the afternoon and in the presence of Caranx melampygus were detected (Table 4). Ctenochaetus strigosus also had a positive correlation with predator presence, but spawning intensity decreased as sunset approached. The other 2 species showed negative correlations with predators, an indication of spawning avoidance during moments of high predatory pressure. For these 2 species spawning intensity peaked during 
Table 2. Multiple regression analyses of the abundance of group-spawning fish species. Normalized abundance data are arcsine transformed. Columns contain the number of 15-min samples used in each model $(\mathrm{N})$, the coefficient of multiple determination for each model $\left(\mathrm{R}^{2}\right)$ and its correspondent $\mathrm{p}$-value, the significant independent model estimators (significant variables), the coefficients of each individual model estimator and the p-value of each of these estimators. Independent variables are time of day, tide, tide ${ }^{2}$ and current direction. Positive coefficients of current direction represent outflowing currents. See 'Methods' section for more details. (NS: not significant)

\begin{tabular}{|c|c|c|c|c|c|c|}
\hline Species & $\mathrm{N}$ & $\mathrm{R}^{2}$ & $\begin{array}{c}\text { Regression } \\
\text { p-value }\end{array}$ & $\begin{array}{l}\text { Significant } \\
\text { variables }\end{array}$ & Coeff. & p-value \\
\hline \multicolumn{7}{|l|}{ Mustin's Gap } \\
\hline \multirow[t]{3}{*}{ Acanthurus nigroris } & 68 & 0.481 & $<0.0001$ & Time of day & 0.204 & $<0.0001$ \\
\hline & & & & Tide & 0.063 & 0.0002 \\
\hline & & & & Tide $^{2}$ & $2.29 \mathrm{E}-04$ & 0.0037 \\
\hline \multirow{4}{*}{ Chlorurus sordidus } & 86 & 0.431 & $<0.0001$ & Current direction & 15.999 & 0.0001 \\
\hline & & & & Time of day & -2.400 & $<0.0001$ \\
\hline & & & & Tide & 0.041 & 0.0188 \\
\hline & & & & Tide $^{2}$ & $-2.14 \mathrm{E}-04$ & 0.005 \\
\hline \multirow[t]{4}{*}{ Zebrasoma flavescens } & 118 & 0.429 & $<0.0001$ & Current direction & 0.388 & $<0.0001$ \\
\hline & & & & Time of day & 0.233 & $<0.0001$ \\
\hline & & & & Tide & 0.003 & NS \\
\hline & & & & Tide $^{2}$ & $-2.89 \mathrm{E}-04$ & $<0.0001$ \\
\hline \multirow{2}{*}{ Ctenochaetus strigosus } & 28 & 0.737 & $<0.0001$ & Current direction & -11.934 & 0.0181 \\
\hline & & & & Time of day & -1.520 & $<0.0001$ \\
\hline \multicolumn{7}{|l|}{ Eastern Reef Edge } \\
\hline Chlorurus sordidus & 32 & - & - & (None) & & NS \\
\hline
\end{tabular}

intermediate (Chlorurus sordidus) and high (Zebrasoma flavescens) outflowing current speeds.

Analyses of dusk pair-spawning species at Mustin's Gap (Table 5) showed no significant correlations between the number of spawns and any of the environmental variables for 2 species (Chaetodon unimaculatus and Parupeneus bifasciatus). Spawning by the other 2 species was only correlated with time of day, Parupeneus multifasciatus decreasing its spawning activity towards sunset and Ostracion meleagris increasing it.
The spawning of daytime pair-spawning labrids greatly varied with environmental conditions (Table 6). Cheilinus unifasciatus had negative correlations with the abundance of both predator species and showed increasing spawning as the day progressed. Spawns by Coris gaimard were positively correlated only with time of day, while the third daytime pair spawner, Epibulus insidiator, showed no significant correlations with any of the environmental variables analyzed.

At the Eastern Reef Edge spawning site, multifactorial analyses of Chlorurus sordidus showed no relation

Table 3. Multiple regression analyses of the number of spawns of group-spawning species. Normalized spawning data are arcsine transformed. Independent variables are time of day, current velocity, current velocity ${ }^{2}$ and abundance of piscivores (Caranx melampygus and Aphareus furca). Details as in legend of Table 2

\begin{tabular}{|c|c|c|c|c|c|c|}
\hline Species & $\mathrm{N}$ & $\mathrm{R}^{2}$ & $\begin{array}{l}\text { Regression } \\
\text { p-value }\end{array}$ & $\begin{array}{l}\text { Significant } \\
\text { variables }\end{array}$ & Coeff. & $\mathrm{p}$-value \\
\hline \multicolumn{7}{|l|}{ Mustin's Gap } \\
\hline Acanthurus nigroris & 43 & 0.164 & 0.007 & Time of day & 0.179 & 0.007 \\
\hline Chlorurus sordidus & 61 & 0.497 & $<0.0001$ & $\begin{array}{l}\text { A. furca } \\
\text { Current velocity } \\
\text { Current velocity }{ }^{2} \\
\text { Time of day }\end{array}$ & $\begin{array}{r}-0.316 \\
1.435 \\
-0.027 \\
-0.232\end{array}$ & $\begin{array}{r}0.0084 \\
<0.0001 \\
<0.0001 \\
<0.0001\end{array}$ \\
\hline Zebrasoma flavescens & 74 & 0.455 & $<0.0001$ & $\begin{array}{l}\text { C. melampygus } \\
\text { Current velocity } \\
\text { Time of day }\end{array}$ & $\begin{array}{r}-0.390 \\
0.657 \\
0.099\end{array}$ & $\begin{array}{c}<0.0001 \\
0.001 \\
0.0307\end{array}$ \\
\hline Ctenochaetus strigosus & 20 & 0.717 & $<0.0001$ & Time of day & -1.841 & $<0.0001$ \\
\hline $\begin{array}{l}\text { Eastern Reef Edge } \\
\text { Chlorurus sordidus }\end{array}$ & 32 & 0.21 & 0.0327 & $\begin{array}{l}\text { Current velocity } \\
\text { Current velocity }^{2}\end{array}$ & $\begin{array}{r}-0.143 \\
0.311\end{array}$ & $\begin{array}{c}\text { NS } \\
0.0098\end{array}$ \\
\hline
\end{tabular}


Table 4. Multiple regression analyses of the spawning intensity rates (number of spawns per fish present) of group-spawning species. Normalized spawning intensity data are log-transformed. Independent variables are time of day, current velocity, current velocity $^{2}$ and abundance of piscivores (Caranx melampygus and Aphareus furca). Details as in legend of Table 2

\begin{tabular}{|c|c|c|c|c|c|c|}
\hline Species & $\mathrm{N}$ & $\mathrm{R}^{2}$ & $\begin{array}{l}\text { Regression } \\
\text { p-value }\end{array}$ & $\begin{array}{l}\text { Significant } \\
\text { variables }\end{array}$ & Coeff. & p-value \\
\hline \multicolumn{7}{|l|}{ Mustin's Gap } \\
\hline Acanthurus nigroris & 63 & 0.152 & 0.0026 & $\begin{array}{l}\text { C. melampygus } \\
\text { Time of day }\end{array}$ & $\begin{array}{l}0.003 \\
0.002\end{array}$ & $\begin{array}{l}0.0167 \\
0.0048\end{array}$ \\
\hline Chlorurus sordidus & 78 & 0.442 & $<0.0001$ & $\begin{array}{l}\text { A. furca } \\
\text { C. melampygus } \\
\text { Current velocity } \\
\text { Current velocity }^{2}\end{array}$ & $\begin{array}{l}-0.005 \\
-0.003 \\
0.032 \\
-5.24 \mathrm{E}-04\end{array}$ & $\begin{aligned} & 0.001 \\
& 0.0037 \\
< & 0.0001 \\
< & 0.0001\end{aligned}$ \\
\hline Zebrasoma flavescens & 118 & 0.4 & $<0.0001$ & $\begin{array}{l}\text { C. melampygus } \\
\text { Current velocity } \\
\text { Current velocity } \\
\text { Time of day }\end{array}$ & $\begin{array}{l}-0.004 \\
0.018 \\
-1.59 \mathrm{E}-04 \\
0.002\end{array}$ & $\begin{array}{r}<0.0001 \\
0.0002 \\
0.0212 \\
0.0013\end{array}$ \\
\hline Ctenochaetus strigosus & 37 & 0.353 & 0.0006 & $\begin{array}{l}\text { Predators } \\
\text { Time of day }\end{array}$ & $\begin{array}{r}0.014 \\
-0.011\end{array}$ & $\begin{array}{l}0.0003 \\
0.0477\end{array}$ \\
\hline Eastern Reef Edge & & & & & & \\
\hline Chlorurus sordidus & 29 & 0.289 & 0.0119 & $\begin{array}{l}\text { Current velocity } \\
\text { Current velocity }^{2}\end{array}$ & $\begin{array}{r}-0.012 \\
0.008\end{array}$ & $\begin{array}{l}0.5102 \\
0.0033\end{array}$ \\
\hline
\end{tabular}

Table 5. Multiple regression analyses of the number of spawns of dusk pair-spawning species. Normalized spawning data are arcsine transformed. Independent variables are time of day, current velocity, current velocity ${ }^{2}$ and abundance of piscivores (average of Caranx melampygus and Aphareus furca). Details as in legend of Table 2

\begin{tabular}{|lccclcc|}
\hline Species & $\mathrm{N}$ & $\mathrm{R}^{2}$ & $\begin{array}{c}\text { Regression } \\
\text { p-value }\end{array}$ & $\begin{array}{l}\text { Significant } \\
\text { variables }\end{array}$ & Coeff. & p-value \\
\hline Cheilinus unimaculatus & 36 & - & - & (None) & NS \\
Ostracion meleagris & 31 & 0.498 & $<0.0001$ & Time of day & 1.827 & $<0001$ \\
Parupeneus bifasciatus & 55 & - & - & (None) & NS \\
Parupeneus multifasciatus & 54 & 0.315 & $<0.0001$ & Time of day & -1.598 & $<0.0001$ \\
\hline
\end{tabular}

Table 6. Multiple logistic model of the number of spawns of daytime pair-spawning species. Columns contain the number of 15min samples used in each model (N), the value of the model loss function, the significant independent model estimators (significant variables), the coefficients of each individual model estimator and their $95 \%$ confidence interval limits. Independent variables are time of day, current velocity, current velocity ${ }^{2}$ and abundance of piscivores (Caranx melampygus and Aphareus furca). See 'Methods' section for more details

\begin{tabular}{|lcclcrr|}
\hline Species & N & $\begin{array}{c}\text { Loss } \\
\text { function }\end{array}$ & $\begin{array}{l}\text { Significant } \\
\text { variables }\end{array}$ & Coeff. & Lower & 95\% CI \\
& & 25.126 & A. furca & -0.038 & -0.064 & 0.077 \\
Cheilinus unifasciatus & 108 & & C. melampygus & -0.03 & -0.052 & -0.007 \\
& & & Time of day & 0.05 & -0.012 \\
Coris gaimard & 117 & 74.322 & Time of day & 2.885 & -0.003 & 0.015 \\
Epibulus insidiator & 42 & - & (None) & & \\
\end{tabular}

between the abundance of fishes and any of the environmental variables analyzed (Table 2). Both spawning and spawning intensity were similarly correlated with current velocity (Tables 3 \& 4), with little spawning occurring at flows close to 0 , and increased spawning with increasing current speeds (in both inflowing and outflowing conditions).
The potential influences by the different environmental variables analyzed in this study on the spawning by reef fishes vary among the different species studied. This wide variety of results can be interpreted for each species according to hypotheses explaining the adaptive values of different diel spawning patterns. 


\section{DISCUSSION}

A first conclusion from this study is the great variability of spawning behaviors used by different species at the same spawning site. Not only did fish spawn at different times of the day, but they had very different responses to other environmental cues such as tides, currents and predators. This wide variety of spawning tactics is well known in coral reef fishes (Thresher 1984, Robertson 1991, Sadovy 1996) and several observational studies have analyzed various species at a single spawning site (Thresher 1982, Robertson 1983, Colin \& Clavijo 1988, Colin \& Bell 1991). In the present study no single explanatory variable was found to include all 11 species studied, as they seemed to utilize the highly variable environmental cues at the spawning grounds in different ways to establish their unique spawning patterns.

Water flow is a crucial environmental factor determining spawning behavior, since it can affect propagule dispersal (Barlow 1981), their exposure to reefbased predators (Johannes 1978) and egg fertilization (Petersen 1991, Petersen et al. 1992). Long-term current meter records at the main spawning site (Mustin's Gap) revealed a flow system that is influenced by tides, but is also affected by wave action, a more unpredictable factor. Variability of water flow with respect to tides is important because tidal cues have been shown to synchronize ovarian development in some reef fishes (Hoffman \& Grau 1989) and to act as local cues for spawning under certain water flow conditions considered selectively beneficial (Johannes 1978, Barlow 1981). Unpredictable flow conditions can be circumvented by postponing the release of gametes upon recognition of 'inappropriate' water flows at the spawning site. To achieve short-term behavioral control of spawning in relation to changing environmental conditions, the endocrine system controlling ovule maturation (Scott 1979) must be plastic enough to allow changes in a short period of time. The sequence from the activation of resting ovarian cells to the appearance of hydrated fertile eggs in the ovarian lumen is poorly understood in tropical reef fishes, but can take place within 24 h (Hoffman \& Grau 1989). Once eggs are hydrated, it is unclear how long they can be retained in the ovary before losing their competency. There are indications that female fish can release eggs for periods of 2 to $4 \mathrm{~h}$ (Fischer \& Hardison 1987, Hoffman \& Grau 1989), and short-term postponement of egg release can occur when predation risks on adults are mimicked (Nemtzov 1994) or spawning is actively disturbed (Lobel \& Neudecker 1985). These data indicate the existence of a behavioral control by female fish on the release of hydrated eggs, probably up to a period of a few hours.
Parrotfishes (Scaridae) have complex social and mating systems which reflect the capacity of individuals to flexibly adapt their spawning behavior to unpredictable environments (van Rooij et al. 1996). Our study observations of Chlorurus sordidus spawning on days with current reversals showed that reef fishes can delay their spawning due to inflowing water flow conditions. Fish aggregated at the spawning site and delayed spawning until currents reversed and became outflowing, interrupting their ongoing spawning if currents reversed again flowing into the lagoon. During this process $C$. sordidus displayed the ability to detect and react to changes in water velocity, responding to differences of $7.3 \mathrm{~cm} \mathrm{~s}^{-1}$ between inflowing and outflowing currents.

\section{Current direction}

One of the main hypotheses addressed by this study is the spawning of gametes exclusively during currents with an outflowing direction away from the natal reef to reduce predation of propagules by benthic predators (Johannes 1978). This pattern has been described in Indo-Pacific reef channels for a variety of species (Robertson 1983, Moyer 1989, Colin \& Bell 1991), even though these studies did not measure water movement in detail. As expected, at Mustin's Gap more daytimespawning species preferentially selected outflowing conditions for spawning (4 of 6 daytime species) than dusk-spawning species (1 of 5 dusk species). This higher selectivity of outflowing conditions by daytime spawners is likely due to their wider diel spawning windows, which allow them to wait for outgoing water flow conditions to occur at the spawning site. Rapidly decreasing light levels just before sunset limit the time available for dusk-spawning species to wait for water flow conditions to change.

Spawning at times that ensure maximum dispersal of propagules away from the spawning site (Barlow 1981) did not occur over long time scales in a Caribbean site with weak wind-driven currents (Appeldoorn et al. 1994, Hensley et al. 1994). In a tidally influenced current system the maximum dispersal has been hypothesized to occur immediately after the onset of an outflowing tidal current (Barlow 1981). No fish were observed to exclusively restrict their spawning to this time at Mustin's Gap. Species that showed spawning bouts immediately after a change to an outflowing current direction also reproduced during tidal moments with steady outflowing currents, indicating that (1) fish are not seeking maximum dispersal of their propagules, or that (2) the onset of outflowing flows does not ensure maximum dispersal away from reefs (a possibility still untested). If this last case is true, then the 
degree of dispersal of propagules probably cannot be predicted by adults. This does not exclude the possibility that some species are attempting to maximize dispersal from reefs, but if adults cannot predict when maximal dispersal will occur, they are likely to display a generalized response to large-scale physical characteristics (Warner 1997). At Mustin's Gap a general response of this kind could be to spawn during outflowing conditions, and not exclusively during the short time frame immediately following the change in current direction. Measurements of benthic predation levels on propagules and dispersal distances from the spawning site under varying flow conditions are needed in order to determine which of the 2 hypothesized selective forces causes certain species to spawn during outgoing flows: risk of benthic predation or maximum dispersal of propagules.

\section{Current speed}

A related larval biology hypothesis predicts coral reef fishes will select fast current velocities for spawning in order to reduce the time spent by propagules over the reef environment (Johannes 1978). Studies relating spawning with current speed (Hunt von Herbing \& Hunte 1991, Appeldoorn et al. 1994, Hensley et al. 1994, Colin 1995) have been done over long time scales in the Caribbean under slow current speed conditions (mostly 0 to $10 \mathrm{~cm} \mathrm{~s}^{-1}$ ) typical of locations with small tidal amplitudes. At Indo-Pacific spawning sites located in reef channels, currents have only been subjectively estimated in spawning studies (Robertson 1983, Moyer 1989, Colin \& Bell 1991). The current speeds measured in this study at Mustin's Gap are of the same magnitude as those from the Deep Entrance at Enewetak Atoll (Atkinson et al. 1981), a channel where large multispecific spawning aggregations have also been described (Thresher \& Brothers 1985, Bell \& Colin 1986, Colin \& Bell 1991).

The present study measured current velocity during short time intervals, so behavioral responses of spawning fishes to rapid changes in local current speed conditions could be detected. At Mustin's Gap only 1 species (Acanthurus nigroris) of the 11 species monitored allocated a significant part of its total spawning to the fastest outflowing current speed category observed at the spawning site (60 to $80 \mathrm{~cm} \mathrm{~s}^{-1}$ ), and only for 1 species (Zebrasoma flavescens) was spawning effort significantly correlated in a positive linear way with current speed. Potential reasons for most species not selecting the fastest current speeds for spawning as predicted by Johannes' hypothesis are (1) low importance of current speed as a selective force determining spawning, (2) unpredictability of the times when the fastest currents occur, (3) reduced egg fertilization rates at very high speeds (Petersen et al. 1992) and (4) existence of a minimum current speed threshold past which no further benefit in avoidance of planktivorous predation is achieved. More detailed research is needed to resolve between these possibilities, since some of the spawning patterns described in this study indicate potentially complex interactions of spawning with current speed.

The 2 group-spawning species with significant correlations between spawning intensity (spawns/fish abundance) and current velocity at Mustin's Gap showed depressions in spawning at both slow and fast flows, with maximum values at intermediate speeds (resulting in parabolic curve fits in the multifactorial analyses). These relationships could result from a combination of the avoidance of slow flows due to high predation risks of propagules, and the avoidance of high flows due to low fertilization rates. Chlorurus sordidus spawning intensity data from the second spawning site (Eastern Reef Edge), where current speeds were much slower, showed increases in spawning with moderately increasing current speed. This pattern is similar to the correlation of $C$. sordidus spawning intensity and moderate current speeds at Mustin's Gap, indicating that $C$. sordidus increased their spawning rates with increasing current speeds in the 0 to $20 \mathrm{~cm}$ $\mathrm{s}^{-1}$ range at 2 different locations.

\section{Time of day}

The existence of diel periodicity in spawning of coral reef fishes has been described in both tidally and nontidally influenced locations (see review by Thresher 1984), with families of fishes spawning at approximately the same time of day across their geographical ranges (Robertson 1983, Gladstone \& Westoby 1988, Sadovy 1996). The 11 species from the present study followed previously described taxonomic patterns, spawning at similar times of the day as other family members at different locations. Time of day by itself seemed to be an important factor determining the timing of spawning in reef fishes at Johnston Atoll (8 of 11 species). Of the 3 species which the multifactorial analyses identified as not spawning at a certain time of the day, 2 of them only spawned during a 2 -h period at dusk (18:00 through 20:00 h). These 2 species were not identified as influenced by time of day because of the short time interval of sampling (60 min) used at dusk, but should be considered as exclusive dusk spawners. In daytime-spawning species, which had long spawning periods, multifactorial analysis indicated the significant influence of a preferred time for spawning in 5 of 6 species. It is unknown why certain families have 
evolved strong preferences for spawning at specific times of the day. Hypotheses on various selective factors affecting larval and adult stages of fishes have been formulated to explain these differences (Robertson 1991), but there is a lack of empirical data supporting any specific hypothesis.

Predatory risks of recently spawned propagules by planktivorous fishes have been hypothesized to affect the timing of spawning of reef fishes (Johannes 1978), and should vary according to time of day. Predation risks are expected to vary among spawning species according to their egg size, among other factors, since larger eggs are easier targets for visual planktivores (Sancho et al. 2000). Size of eggs varies consistently among families of pelagic-spawning fishes (Thresher 1984, Duarte \& Alcaraz 1989), and families of reef fishes with large eggs are expected to spawn latest in the day, after most of the diurnal planktivorous fishes have stopped feeding due to low light levels (Hobson 1973, 1991). Trunkfishes (Ostraciidae) have unusually large eggs (1.4 to $2 \mathrm{~mm}$ in diameter) when compared to most other families of pelagic-spawning reef fishes (Thresher 1984), and predictably, trunkfishes are typically dusk-spawning species (Moyer 1979, Sancho 1998). As expected, at Mustin's Gap the trunkfish Ostracion meleagris displayed a tendency of spawning after sunset, much later than any of the other duskspawning species analyzed in this study.

\section{Tides}

Reef fishes have been proposed to use tides as cues to synchronize spawning (Colin \& Clavijo 1988). This hypothesis implies that tidal flows are not important in the selection of spawning times, but that hydrostatic pressure is a useful cue for migration to the spawning grounds, reducing the time spent by fish in spawning activities and allowing more time for other activities such as feeding. Indo-Pacific reef fishes are capable of synchronizing their ovarian cycles with local tidal cycles (Hoffman \& Grau 1989). But IndoPacific reef fishes described as following tidal spawning cycles preferentially spawn at the tidal stage that is most likely to produce a transport of propagules away from the reef system (Randall 1961, Robertson \& Hoffman 1977, Johannes 1978, Lobel 1978, Thresher 1979, Kuwamura 1981, Tribble 1982, Warner 1982, Robertson 1983, Ross 1983, Bell \& Colin 1986, Moyer 1989, Colin \& Bell 1991), either during flood or ebb tides. This indicates than even though tides can be used as a synchronizing cue for spawning, larval transport may be the crucial factor determining spawning periodicity in locations with significant tidal amplitudes.
At Mustin's Gap, 7 out of 11 species spawned more intensively during flood tides, which is the period when the currents are most likely to flow away from the reef. Of the other 4 species, 1 spawned mostly during ebb tides and 3 species showed no preference for either tide cycle. Group-spawning species showing tidal influences on spawning were present in high abundance at the spawning grounds for extended periods of time, which does not indicate a reduction of time allocated to spawning activities as expected considering the above hypothesis. The abundance estimates of all group-spawning species were also significantly correlated with a specific time of day, another cyclic variable which can be used to synchronize ovarian cycles in reef fishes (Fischer \& Hardison 1987).

Populations of Chlorurus sordidus spawn during flood tides at Johnston Atoll and during ebb tides in other locations (Moyer 1989, Colin \& Bell 1991), depending on when in the tidal cycle outflowing currents occur. This indicates that a specific tidal phase is not used as a fixed environmental cue across the geographic range of this species, but that fish are responding to directional water flows.

At the Eastern Reef Edge spawning site Chlorurus sordidus spawned during a brief period after low tide. There appears to be no clear advantage to spawning at this time for larval transport due to the unpredictable current direction. But the Eastern Reef Edge spawning site was located along the migration route to a much larger aggregation site located farther east along the submerged reef edge of the Atoll (G.S. pers. obs.). The tidal periodicity in spawning activities measured at the Eastern Reef Edge site are likely a secondary result of the periodicity existent at the nearby larger spawning site, where strong tidally influenced currents are expected to occur because of its location at the reef crest (no current meter deployments were possible at this site due to very strong surf). Current speeds at the Eastern Reef Edge were fastest after low tide and were within the range of speed values selected by $C$. sordidus, so the observed spawning pattern could actually have a potential effect on larval survivorship by reducing time of exposure to benthic predators (Johannes 1978).

\section{Predation of adults}

Predation risks on adult spawning fish have been proposed on numerous occasions as a potential factor controlling the timing of spawning of coral reef fishes, but there is a lack of information on diel activity patterns at spawning grounds of piscivores and on specific interactions of these predators with their prey (Robertson 1991). Information resulting from this study on the specific be- 
havior of predators at spawning grounds is presented elsewhere (Sancho 2000, Sancho et al. 2000). Our results regarding the relation of spawning intensity to abundance of predators illustrate the effects of predation in determining spawning behavior in certain species. For example, the overall risk of predation was much lower at dusk than during daytime hours (Sancho et al. 2000), which explains the indifference of all 6 dusk-spawning species to the abundance levels of piscivores.

Species of reef fishes with specific antipredatory adaptations are also hypothesized to have decreased risks of predation and to spawn independently of the predatory activity of piscivores (Gladstone \& Westoby 1988). Therefore parrotfishes such as Chlorurus sordidus should have been most affected by predatory risks, since they were abundant at the spawning grounds, spawn during daytime hours and lack antipredatory morphological adaptations (Godin 1997, Smith 1997). As expected parrotfishes showed reduced spawning intensities when predators were abundant, but other predator-prey relations observed were not predicted by the previous argument. The most abundant surgeonfish, Acanthurus nigroris, seemed to spawn unaffected by predator activities, as originally expected due to its antipredatory morphological adaptations. However, the observation of high predatory rates on this species, and capture rates comparable to those of parrotfishes (Sancho et al. 2000), indicate that piscivores can successfully prey on A. nigroris populations, and therefore predator activity should have caused reduced spawning intensity in this surgeonfish. In addition, unexpected reductions in spawning intensity of 2 species of large size and with anti-predatory morphological defenses (Cheilinus unifasciatus and Zebrasoma flavescens) were observed during moments of high abundance of piscivores. In conclusion, timing of spawning seemed to be affected by piscivore activities in daytime-spawning species, independently of specific antipredatory adaptations.

The reduction of spawning intensity in response to piscivores implies, as the delay of spawning during inflowing currents did, that female reef fishes are capable of postponing or aborting the release of hydrated eggs under local environmental conditions. The most vulnerable moment in a spawning sequence is during the spawning rush (Moyer 1987, Sancho et al. 2000). Various changes in spawning behavior of prey could explain the reduced spawning intensities during moments of high predatory risks: (1) elimination of the spawning rush, releasing eggs among the coral heads (Lobel \& Neudecker 1985), (2) delay of spawning until predator abundance diminishes (Nemtzov 1994), (3) migration and spawning at another location and (4) interruption of spawning and re-absorption of gametes. Re-absorption of eggs has not been observed in coral reef pelagic spawners, and it is considered an unlikely explanation since most coral reef fishes are batch spawners (Sadovy 1996) and can have egg maturation cycles as short as $24 \mathrm{~h}$ (Hoffman \& Grau 1989). No significant energetic benefit is expected from egg reabsorption in coral reef fishes. The other explanations which involve release of eggs are more plausible, but more specific studies on predator-prey relationships at spawning grounds are necessary to resolve among these possibilities.

\section{Summary}

The diel timing patterns of spawning in coral reef fishes were very diverse and seemed to be influenced by a variety of environmental factors. Correlations between spawning and outgoing flows indicated that dispersal of propagules away from the reef environment may be an important selective force for daytimespawning species, which on occasion showed the ability to postpone spawning until flow direction was appropriate. Spawning at high current speeds was a rare pattern among the species studied, which were exposed to a relatively high range of current speeds. Most species analyzed had a peak of maximum spawning activity, with daytime spawners displaying a large variability of times for spawning and dusk spawners more restricted spawning times. Tides did not seem to be used as synchronizing cues for spawning by fish migrating to the spawning sites. The presence of piscivorous fishes was negatively correlated with the spawning intensity of a few species, while the majority of species showed no correlation.

Results indicating the importance of outflowing currents as an environmental cue for various species support the validity of either the hypothesis proposing maximum dispersal of propagules away from reefs (Barlow 1981) or the hypothesis proposing reduction of reef-based predation of propagules (Johannes 1978). Both mechanisms may be controlling the timing of reproduction. The avoidance of predation risks by adults (Robertson 1991) can also influence the spawning patterns of certain species.

Warner $(1991,1997)$ hypothesized about the mechanisms employed by reef fishes to develop local adaptations to their adult environment, since they have a dispersive larval stage. The mechanisms involve (1) finely tuned responses by adult fishes to detectable local environmental cues, or (2) fixed responses across the range of a species when certain environmental factors cannot be detected by the adults (Warner 1997). The present study suggests that current direction and predatory risks are environmental cues that can be detected by adult fishes and elicit reproductive 
responses in very short time scales. In contrast, time of day seems to elicit a fixed reproductive response among fish of the same family across wide distribution areas. Daytime spawners tend to display short-term spawning responses to local changes in the environment, while dusk spawners show few locally adapted reproductive responses. Dusk spawners potentially benefit from reduced predatory risks occurring at dusk. The existence of species spawning during different tidal cycles at different locations indicates that tides are not used as fixed environmental cues for spawning, but that fishes are likely responding to associated directional water flows. The importance of current speed as an environmental variable influencing spawning varied among species, some avoiding spawning at very low current speeds.

More studies quantifying both spawning output and variability of environmental cues in other locations are needed to analyze the geographic variability in spawning patterns and the specific plasticity of decision mechanisms leading to the potential establishment of locally adapted spawning patterns.

Acknowledgements. We thank Lauren Mullineaux, Deborah Bidwell, Glenn Flierl, Gary Jaroslow, David Mann, Anna Metaxas, Chris Petersen and 3 anonymous reviewers for invaluable comments on early drafts of this paper. Alistair Economakis, Diana Ma, David Mann and Steve Oliver provided essential help during the diving operations at Johnston Atoll. This study was supported by a 'La Caixa' fellowship to G.S. and by grants to P.S.L. from the US Army Chemical Material Destruction Agency (via NOAA Sea Grant NA90AA-D-SG535 and the Office of Naval Research N00014-91-J1591 and N00014-92-J-1969, and the Office of Army Research DAAG 55-98-1-0304) and the US Army Legacy Resource Management Program (DAMD 17-93-J-3052). This work was submitted as part of G.S.'s PhD thesis to the WHOI/MIT Joint Program in Oceanography. Contribution 10121 of the Woods Hole Oceanographic Institution.

\section{LITERATURE CITED}

Appeldoorn RS, Hensley DA, Shapiro DY, Kioroglou S, Sanderson BG (1994) Egg dispersal in a Caribbean coral reef fish, Thalassoma bifasciatum. II. Dispersal off the reef platform. Bull Mar Sci 54:271-280

Atkinson M, Smith SV, Stroup ED (1981) Circulation in Enewetak Atoll lagoon. Limnol Oceanogr 26:1074-1083

Barlow GW (1981) Patterns of parental investment, dispersal and size among coral-reef fishes. Environ Biol Fishes 6: 65-85

Bell LJ, Colin PL (1986) Mass spawning of Caesio teres (Pisces:Caesionidae) at Enewetak Atoll, Marshall Islands. Environ Biol Fishes 15:69-74

Clavijo IE (1983) Pair spawning and formation of a lek-like mating system in the parrotfish Scarus vetula. Copeia 1983:253-256

Colin PL (1995) Surface currents in Exuma Sound, Bahamas and adjacent areas with reference to potential larval transport. Bull Mar Sci 56:48-57
Colin PL, Bell LJ (1991) Aspects of spawning of labrid and scarid fishes (Pisces: Labroidei) at Enewetak Atoll, Marshall Islands with notes on other families. Environ Biol Fishes 31:229-260

Colin PL, Clavijo IE (1978) Mass spawning by the spotted goatfish, Pseudupeneus maculatus (Bloch) (Pisces: Mullidae). Bull Mar Sci 28:780-782

Colin PL, Clavijo IE (1988) Spawning activity of fishes producing pelagic eggs on a shelf edge coral reef, southwestern Puerto Rico. Bull Mar Sci 42:249-279

Collett B (1991) Modelling binary data. Chapman and Hall, London

Duarte CM, Alcaraz M (1989) To produce many small or few large eggs: a size-independent reproductive tactic of fish. Oecologia 80:401-404

Fischer EA, Hardison PD (1987) The timing of spawning and egg production as constraints on male mating success in a simultaneously hermaphroditic fish. Environ Biol Fishes 20:301-310

Gladstone W, Westoby M (1988) Growth and reproduction in Canthigaster valentini (Pisces: Tetraodontidae): a comparison of a toxic reef fish with other reef fishes. Environ Biol Fishes 21:207-221

Godin JGJ (1997) Evading predators. In: Godin JGJ (ed) Behavioral ecology of teleost fishes. Oxford University Press, Oxford, p 191-236

Hensley DA, Appeldoorn RS, Shapiro DY, Ray M, Turingan RG (1994) Egg dispersal in a Caribbean coral reef fish, Thalassoma bifasciatum. I. Dispersal over the reef platform. Bull Mar Sci 54:256-270

Hobson ES (1973) Activity of Hawaiian reef fishes during the evening and morning transitions between daylight and darkness. Fish Bull US 70:715-740

Hobson ES (1991) Trophic relationships of fishes specialized to feed on zooplankters above coral reefs. In: Sale PF (ed) The ecology of fishes on coral reefs. Academic Press, San Diego, p 69-95

Hoffman KS, Grau EG (1989) Daytime changes in oocyte development with relation to the tide for the Hawaiian saddleback wrasse, Thalassoma duperrey. J Fish Biol 34: 529-546

Hunt von Herbing I, Hunte W (1991) Spawning and recruitment of the bluehead wrasse Thalassoma bifasciatum in Barbados, West Indies. Mar Ecol Prog Ser 72:49-58

Johannes RE (1978) Reproductive strategies of coastal marine fishes in the tropics. Environ Biol Fishes 3:65-84

Kuwamura T (1981) Diurnal periodicity of spawning activity in free-spawning labrid fishes. Jpn J Ichthyol 28:343-348

Lobel PS (1978) Diel, lunar, and seasonal periodicity in the reproductive behavior of the pomacanthid fish Centropyge potteri, and some other reef fishes in Hawaii. Pac Sci 32: 193-207

Lobel PS, Neudecker S (1985) Diurnal periodicity of spawning activity by the hamlet fish, Hypoplectrus guttavarius (Serranidae). In: Reaka ML (ed) The ecology of coral reefs, Vol. 3. NOAA Undersea Research Program, Rockville, $\mathrm{MD}, \mathrm{p}$ 71-86

Meyer KA (1977) Reproductive behavior and patterns of sexuality in the Japanese labrid fish Thalassoma cupido. Jpn J Ichthyol 24:101-112

Miller RG (1986) Beyond ANOVA, basics of applied statistics. John Wiley and Sons, New York

Morgan SG (1996) Plasticity in reproductive timing by crabs in adjacent tidal regimes. Mar Ecol Prog Ser 139:105-118

Morgan SG, Christy JH (1994) Plasticity, constraint, and optimality in reproductive timing. Ecology 75:2185-2203

Moyer JT (1979) Mating strategies and reproductive behavior 
of ostraciid fishes at Miyake-jima, Japan. Jpn J Ichthyol 26:148-160

Moyer JT (1987) Quantitative observations of predation during spawning rushes of the labrid fish Thalassoma cupido at Miyake-jima, Japan. Jpn J Ichthyol 34:76-81

Moyer JT (1989) Reef channels as spawning sites for fishes on the Shiraho coral reef, Ishigaki Island, Japan. Jpn J Ichthyol 36:371-375

Moyer JT, Yogo Y (1982) The lek-like mating system of Halichoeres melanochir (Pisces: Labridae) at Miyake-jima, Japan. Z Tierpsychol 60:209-226

Myrberg AA, Montgomery WL, Fishelson L (1989) The reproductive behavior of Acanthurus nigrofuscus (Forskal) and other surgeonfishes (Fam. Acanthuridae) off Eilat, Israel (Gulf of Aqaba, Red Sea). Ethology 79:31-61

Nemtzov SC (1994) Intraspecific variation in sand-diving and predator avoidance behavior of green razorfish, Xyrichtys splendens (Pisces: Labridae): effect on courtship and mating suscess. Environ Biol Fishes 41:403-414

Petersen CW (1991) Variation in fertilization rate in the tropical reef fish Halichoeres bivittatus: correlates and implications. Biol Bull (Woods Hole) 181:232-237

Petersen CW, Warner RR, Cohen S, Hess HC, Sewell AT (1992) Variable pelagic fertilization success: implications for mate choice and spatial patterns of mating. Ecology 73: 391-401

Randall JE (1961) Observations on the spawning of surgeonfishes (Acanthuridae) in the Society Islands. Copeia 2: 237-288

Robertson DR (1982) Gonochorism, protogynous sex-change and spawning in three Sparisomatinine parrotfishes from the western Indian Ocean. Bull Mar Sci 32:868-879

Robertson DR (1983) On the spawning behavior and spawning cycles of eight surgeonfishes (Acanthuridae) from the Indo-Pacific. Environ Biol Fishes 9:193-223

Robertson DR (1991) The role of adult biology in the timing of spawning of tropical reef fish. In: Sale PF (ed) The ecology of fishes on coral reefs. Academic Press, San Diego, p 356-386

Robertson DR, Hoffman SG (1977) The roles of female mate choice and predation in mating systems of some tropical labroid fishes. Z Tierpsychol 45:298-320

Robertson DR, Warner RR (1978) Sexual patterns in the labroid fishes of the western Caribbean. II. The parrotfishes (Scaridae). Smithson Contrib Zool 255:1-26

Robertson DR, Petersen CW, Brawn JD (1990) Lunar reproductive cycles of benthic-brooding reef fishes: reflections of larval biology or adult biology? Ecol Monogr 60:311-329

Ross RM (1983) Annual, semilunar, and diel reproductive rhythms in the Hawaiian labrid Thalassoma duperrey. Mar Biol 72:311-318

Sadovy YJ (1996) Reproduction of reef fishery species. In: Polunin NVC, Roberts CM (eds) Reef fisheries, Vol 20. Chapman and Hall, London, p 15-59

Editorial responsibility: Otto Kinne (Editor), Oldendorf/Luhe, Germany
Sancho G (1998) Factors regulating the height of spawning ascents in trunkfishes (Ostraciidae). J Fish Biol 53 (Suppl A): $94-103$

Sancho G (2000) Predatory behaviors of Caranx melampygus (Carangidae) feeding on spawning reef fishes: a novel ambushing strategy. Bull Mar Sci 66(2):487-496

Sancho G, Petersen CW, Lobel PS (2000) Predator-prey relations at a spawning aggregation site of coral reef fishes. Mar Ecol Prog Ser 203:275-288

Scott DBC (1979) Environmental timing and the control of reproduction in teleost fish. Symp Zool Soc Lond 44:105-132

Shapiro DY, Hensley DA, Appledoorn RS (1988) Pelagicspawning and egg transport in coral-reef fishes: a skeptical overview. Environ Biol Fishes 22:3-14

Shibuno T, Gushima K, Kakuda S (1993) Female spawning migrations of the protogynous wrasse, Halichoeres marginatus. Jpn J Ichthyol 39:357-362

Smith RJF (1997) Avoiding and deterring predators. In: Godin JGJ (ed) Behavioral ecology of teleost fishes. Oxford University Press, Oxford, p 163-189

Sokal RR, Rohlf FJ (1995) Biometry. WH Freeman and Co, New York

Thresher RE (1979) Social behavior and ecology of 2 sympatric wrasses (Labridae: Halichoeres spp.) off the coast of Florida. Mar Biol 53:161-172

Thresher RE (1982) Courtship and spawning in the emperor angelfish Pomacanthus imperator, with comments on reproduction by other pomacanthid fishes. Mar Biol 70: 149-156

Thresher RE (1984) Reproduction in reef fishes. TFH Publications, Neptune City, NJ

Thresher RE, Brothers EB (1985) Reproductive ecology and biogeography of Indo-West Pacific angelfishes (Pisces: Pomacanthidae). Evolution 39:878-887

Tribble GW (1982) Social organization, patterns of sexuality, and behavior of the wrasse Coris dorsomaculata at Miyake-jima, Japan. Environ Biol Fishes 7:29-38

van Rooij JM, Kroon FJ, Videler JJ (1996) The social and mating system of the herbivorous reef fish Sparisoma viridae: one-male versus multi-male groups. Environ Biol Fishes 47:353-378

Warner RR (1982) Mating systems, sex change and sexual de mography in the rainbow wrasse, Thalassoma lucasanum. Copeia 1982:653-661

Warner RR (1991) The use of phenotypic plasticity in coral reef fishes as tests of theory in evolutionary ecology. In: Sale PF (ed) The ecology of fishes on coral reefs. Academic Press, San Diego, p 387-398

Warner RR (1997) Evolutionary ecology: how to reconcile pelagic dispersal with local adaptation. Coral Reefs 16 (Suppl):115-120

Warner RR, Robertson DR (1978) Sexual patterns in the labroid fishes of the western Caribbean. I. The wrasses (Labridae). Smithson Contrib Zool 254:1-27

Submitted: September 16, 1999; Accepted: February 10, 2000 Proofs received from author(s): October 9, 2000 